\title{
Alpine snow cover in a changing climate: a regional climate model perspective
}

\author{
Christian Steger • Sven Kotlarski • Tobias Jonas • \\ Christoph Schär
}

Received: 20 April 2012/Accepted: 25 September 2012/Published online: 16 October 2012

(C) Springer-Verlag Berlin Heidelberg 2012

\begin{abstract}
An analysis is presented of an ensemble of regional climate model (RCM) experiments from the ENSEMBLES project in terms of mean winter snow water equivalent (SWE), the seasonal evolution of snow cover, and the duration of the continuous snow cover season in the European Alps. Two sets of simulations are considered, one driven by GCMs assuming the SRES A1B greenhouse gas scenario for the period 1951-2099, and the other by the ERA-40 reanalysis for the recent past. The simulated SWE for Switzerland for the winters 1971-2000 is validated against an observational data set derived from daily snow depth measurements. Model validation shows that the RCMs are capable of simulating the general spatial and seasonal variability of Alpine snow cover, but generally underestimate snow at elevations below $1,000 \mathrm{~m}$ and overestimate snow above $1,500 \mathrm{~m}$. Model biases in snow cover can partly be related to biases in the atmospheric forcing. The analysis of climate projections for the twenty first century reveals high inter-model agreement on the following points: The strongest relative reduction in winter mean SWE is found below $1,500 \mathrm{~m}$, amounting to $40-80 \%$ by mid century relative to $1971-2000$ and depending upon the model considered. At these elevations, mean winter temperatures are close to the melting point.
\end{abstract}

Electronic supplementary material The online version of this article (doi:10.1007/s00382-012-1545-3) contains supplementary material, which is available to authorized users.

C. Steger · S. Kotlarski $(\square) \cdot$ C. Schär

Institute for Atmospheric and Climate Science,

ETH, Zurich, Switzerland

e-mail: sven.kotlarski@env.ethz.ch

T. Jonas

WSL Institute for Snow and Avalanche Research SLF,

Davos, Switzerland
At higher elevations the decrease of mean winter SWE is less pronounced but still a robust feature. For instance, at elevations of 2,000-2,500 m, SWE reductions amount to $10-60 \%$ by mid century and to $30-80 \%$ by the end of the century. The duration of the continuous snow cover season shows an asymmetric reduction with strongest shortening in springtime when ablation is the dominant factor for changes in SWE. We also find a substantial ensemble-mean reduction of snow reliability relevant to winter tourism at elevations below about $1,800 \mathrm{~m}$ by mid century, and at elevations below about $2,000 \mathrm{~m}$ by the end of the century.

Keywords Climate change $\cdot$ Regional climate projections - European Alps - Snow water equivalent . Snow cover duration $\cdot$ ENSEMBLES

\section{Introduction}

Snow cover is a key component of the climate system. The low thermal conductivity of snow insulates the underlying ground from atmospheric temperatures and the relatively high albedo of snow alters the ground energy fluxes considerably compared to snow-free ground (Armstrong and Brun 2008). The related snow-albedo feedback is considered as one of the most important feedback mechanisms in the global climate system (Hall 2004). The occurrence of snow cover is crucial for ecology as hibernating animals and the seasonal vegetation cycle strongly depend on the timing of the snow season (Jonas et al. 2008; Marchand 1996). In regions with widespread human activities such as the European Alps snow cover also has a high economical significance. The storage of water in form of snow is relevant for water resources and hydropower production (Armstrong and Brun 2008; Voigt et al. 2010) and snow 
reliability is of major importance for winter tourism (Elsasser and Buerki 2002).

Snow cover dynamics in the Alps in the twentieth century reveal non-uniform trends and patterns. The mean snow depth and the duration of continuous snow cover in the Swiss Alps showed a gradual increase until the early 1980s, followed by a significant decrease towards the end of the century. These changes were most pronounced at mid and low altitudes (Laternser and Schneebeli 2003). The number of snow days in the Swiss Alps showed a steplike decrease in the late 1980s at all altitudes with no clear trend towards the end of the century (Marty 2008). Observed reductions in Alpine snow cover can mainly be attributed to local temperature increases whereas the impact of precipitation changes is comparably small (Scherrer and Appenzeller 2006). Accordingly, Hantel and Maurer (2011) found that snow cover duration in the Alps seems to exhibit a strong sensitivity to mean European temperatures. The highest sensitivity of snow cover to temperature variations is found at low altitudes, which can be explained by a general temperature level at these elevations close to the melting point. Large-scale phenomena such as the North Atlantic Oscillation and the transition from solar dimming to solar brightening may be responsible for the pronounced snow cover changes in the 1980s (Henderson and Leathers 2010; Marty 2008; Norris and Wild 2007).

Available climate projections for the Alpine area for the twenty first century mostly agree on the sign of changes in snow parameters. The majority of global climate models from the World Climate Research Programme CMIP3 multi-model dataset indicate a significant decrease in snow cover duration in Central Europe during the twenty first century. Also decreases in the maximum snow water equivalent (SWE) are significant for more than $50 \%$ of the models (Brown and Mote 2009). Studies based on highresolution energy balance and land surface models support these findings: The projected reduction of snow volume in the Swiss Alps by the end of the twenty first century amounts to about $90 \%$ at elevations close to $1,000 \mathrm{~m}$ and to about $35 \%$ at elevations close to 3,000 m (Beniston et al. 2003). For two alpine catchments in eastern Switzerland Bavay et al. (2009) found a reduction of the maximal SWE of more than $30 \%$ by 2100 . The relative reduction of snow depth was found to be more pronounced at lower elevations. In addition to changes of mean and maximum SWE, climate change is also expected to lead to changes in the timing of peak SWE (Bavay et al. 2009; Martin and Etchevers 2005) and to a general shortening of the snow cover season (Beniston et al. 2003; Magnusson et al. 2010). The mentioned studies consistently show that the response of snow cover to climatic changes can be subject to a pronounced and complex elevation dependency with low-elevation regions typically showing the strongest sensitivity. This can partly be explained by the warmer temperature level at low elevations, but for parameters such as maximum SWE also non-linear interactions between the duration of the snow season and snow accumulation rates are of importance (e.g. Brown and Mote 2009). The elevation-dependent response of snow cover is also connected to the elevation dependency of changes in the atmospheric forcing parameters themselves (e.g. Fyfe and Flato 1999; Giorgi et al. 1997; Kotlarski et al. 2012; Rangwala and Miller 2012). Projected twenty first century snow cover changes are expected to have strong implications for hydropower production (Kobierska et al. 2012) as well as for winter tourism (Abegg et al. 2007). Simulated snow reliability for three ski areas in western Austria has been assessed by Steiger (2010) who found that only the ski area with the highest mean elevation $(1,900 \mathrm{~m})$ is snow reliable beyond 2,050 without artificial snowmaking.

The results of the mentioned studies emphasize that the sensitivity of snow parameters to climatic variability and climatic changes does not only depend on elevation but also on site-specific topographic and climatic conditions (e.g. exposition and terrain shading). It is thus unsurprising that horizontal resolution was identified to play a crucial role in characterizing and modeling snow cover over complex terrain (e.g. Dutra et al. 2011). Recent studies investigating future snow cover changes thus use dedicated high-resolution land surface models or energy balance models driven by prescribed changes of climatic parameters provided by a General Circulation Model (GCM) or a Regional Climate Model (RCM). The advantage of such an offline coupling is the ability to capture some of the smallscale processes of snow physics. These processes strongly determine snow accumulation and ablation on a local scale and, at the same time, strongly depend on the topography and further physiographic features. The latter are only approximately captured by climate models due to their relatively coarse spatial resolution. There are, however, a number of disadvantages when evaluating such an offline model chain. First of all, the downscaling methods that are applied to GCM or RCM results in order to bridge the scale gap and to correct for model biases introduce new uncertainties into the data (e.g. Bosshard et al. 2011; Lenderink et al. 2007; Wood et al. 2004). Furthermore, downscaling and post-processing of climate model output can lead to inconsistencies between different atmospheric forcing parameters: While, for instance, temperature and precipitation data in raw climate model output can be expected to be physically consistent with each other, this is not necessarily the case for downscaled and/or post-processed climate model output (e.g. Fowler et al. 2007). A further issue is the double accounting of land surface processes including snow physics. Climate models make use of 
simplified hydrological and land surface sub-models which potentially feed back to the model's atmosphere. Linking a climate model's atmospheric output to a land surface model that strongly differs from the climate model's online scheme might therefore generate inconsistencies between the applied atmospheric forcing and the state of the land surface.

As an alternative, the analysis of snow cover characteristics as directly simulated by the land surface schemes of climate models (e.g. Brown and Mote 2009; Dutra et al. 2011; Räisänen and Eklund 2012; Salzmann and Mearns 2011) ensures inter-parameter consistency and becomes increasingly attractive given the continuously increasing resolution of both global and regional climate models. In the latter case, current operational resolutions for centurylong simulations range between 10 and $50 \mathrm{~km}$. This already allows to describe important topographic features in mountainous terrain and to cover high elevations that are not represented by the strongly smoothed topography of GCMs. Still, small scale topographic variability is not accounted for which obviously limits the applicability to regional and continental scales and often requires an additional downscaling of RCM results to the site scale. Furthermore, although based on energy balance approaches, snow parameterization schemes of current global and regional climate models are often of a strongly simplified nature compared to dedicated models of the surface snow pack. Their main purpose is to provide a realistic surface forcing for the model's atmospheric component in terms of snow-covered area, surface albedo and surface temperature. In many cases, simple one- or two-layer schemes are applied that do not allow to represent details of snow metamorphism. Important processes such as the refreezing of melt water within the snow pack are typically not accounted for. For illustration and as an example, Figure ESM 1 of the Electronic Supplementary Material (ESM) schematically presents the one-layer snow scheme of the regional climate model COSMO-CLM (Rockel et al. 2008). Given the inherent imperfections of climate models it also has to be considered that the land surface scheme of a climate model might be exposed to a strongly biased atmospheric forcing. Hence, any analysis of snow cover characteristics as simulated by climate models needs to be related to the ability of the climate model to generate a realistic atmospheric forcing.

In a recent study, Räisänen and Eklund (2012) analyzed regional climate model output of the ENSEMBLES project (van der Linden and Mitchell 2009) to assess future snow cover changes in northern Europe. The authors found that all models collectively indicate a future decrease in SWE, particularly in regions with a relatively mild winter climate. In the present study we focus on the European Alps, a topographically strongly structured region in central
Europe. Analyzing an extended set of RCM experiments of the ENSEMBLES project at $25 \mathrm{~km}$ horizontal resolution we try to answer the following questions: (1) How reliably can current RCMs reproduce snow cover characteristics in the mountainous terrain of the European Alps if driven by a realistic boundary forcing (reanalysis) and by free-running GCMs? (2) How do the same RCMs simulate snow cover changes in this region during the twenty first century? (3) To what extent do the simulated snow cover changes depend on elevation, and finally (4) how large is the model uncertainty with respect to snow cover projections and which signals are robust? In addressing these questions we will mostly consider the parameters (1) mean winter SWE (2) seasonal cycle of SWE and (3) the duration of the snow season.

The following chapter gives an overview on the data sets used and on the methodological details. Chapter 3 presents the model validation for the period 1971-2000, and Chapter 4 provides climate change projections for the twenty first century. The study is concluded in Chapter 5. Supporting figures, mainly concerning the SWE validation of the GCM-driven experiments and the analysis of temperature and precipitation, are provided in the Electronic Supplementary Material (referred to as ESM hereafter).

\section{Data and methods}

\subsection{Regional climate model data}

Our analysis is based on RCM simulations for Europe conducted within the ENSEMBLES project (van der Linden and Mitchell 2009). They include both reanalysisdriven experiments for the second part of the twentieth century and GCM-driven simulations from the mid twentieth century to the end of the twenty first century. An improvement with respect to the precursor project PRUDENCE (Christensen and Christensen 2007) is the refinement of the grid and the larger set of driving GCMs which allows for a more comprehensive assessment of GCMrelated uncertainties in the modeling chain. From all RCMs of the ENSEMBLES project, the ones with a resolution of about $25 \mathrm{~km}$ and available snow data at daily resolution were selected for this study (see Table 1). The reanalysis product used for driving the 14 RCMs is ERA40 which was produced by the European Centre for Medium-Range Weather Forecast in collaboration with several further institutions (Uppala et al. 2005). Out of the GCM-driven RCMs, 18 experiments fulfilled the requirements mentioned above. A similar set of experiments has recently been used to derive regional climate change scenarios for Switzerland (CH2011 2011). All driving GCMs assume the IPCC SRES A1B emission scenario. This scenario is part 
Table 1 The RCMs used for this study

\begin{tabular}{llll}
\hline Institute & RCM & Driving GCM & $\begin{array}{l}\text { Climate } \\
\text { projection period }\end{array}$ \\
\hline C4I & RCA3 & HadCM3Q16 & $1951-2099$ \\
CNRM & Aladin & ARPEGE & $1951-2050$ \\
DMI & HIRHAM & ARPEGE & $1951-2099$ \\
& & BCM & $1951-2099$ \\
& & ECHAM5 & $1951-2099$ \\
EC & GEMLAM & - & - \\
ETHZ & CLM & HadCM3Q0 & $1951-2099$ \\
METO & HadRM3Q0 & HadCM3Q0 & $1951-2099$ \\
& HadRM3Q3 & HadCM3Q3 & $1951-2099$ \\
& HadRM3Q16 & HadCM3Q16 & $1951-2099$ \\
KNMI & RACMO & ECHAM5 & $1951-2099$ \\
METNO & HIRHAM & BCM & $1951-2050$ \\
& & HadCM3Q0 & $1951-2050$ \\
MPI & REMO & ECHAM5 & $1951-2099$ \\
OURANOS & CRCM & CGCM3 & $1951-2050$ \\
SMHI & RCA & BCM & $1951-2099$ \\
& & ECHAM5 & $1951-2099$ \\
& & HadCM3Q3 & $1951-2099$ \\
UCLM & PROMES & HadCM3Q0 & $1951-2050$ \\
\hline
\end{tabular}

The acronyms for the institutes and models were adopted from the ENSEMBLES RCM data portal (http://ensemblesrt3.dmi.dk). The ERA40-driven runs are simply referred to by the institute's name (e.g. C4I; except for METO where the model version is additionally given), the GCM-driven runs by the combination Institute-Driving GCM (e.g. C4I-HadCM3Q16)

of the A1 scenario family that assumes a world of very rapid economic growth, a global population that peaks in mid-century and a rapid introduction of new and more efficient technologies. A1B thereby describes a balanced direction of technological change (Nakicenovic and Swart 2000), resulting in an atmospheric $\mathrm{CO}_{2}$ concentration of about 700 ppm by 2100 .

The analysis domain for model validation is constrained to Switzerland since the observational reference data set is limited to this region (see below). For the climate projection part the analysis domain covers the entire Alps and the surrounding lowlands (Fig. 1).

\subsection{Observational data}

To validate the simulated RCM snow cover we used longterm data from several Swiss snow monitoring networks. This dataset comprises daily snow depth readings from 110 stations throughout Switzerland continuously available since 1970. The stations cover all regions and elevations within Switzerland with a good network density (Fig. 2), except that long-term data for elevations above 2,100 m are scarce (1 station only). Measured snow depth data were converted to SWE using a snow density model based on Jonas et al. (2009). The model was chosen as it was calibrated using 11,000 snow profiles from the same snowmonitoring networks that also provided the snow depth data.

To mitigate the problem of comparing station data (point scale) with coarse resolution model output $(25 \mathrm{~km}$ resolution), all observational data were first mapped to the common RCM grid and the ensemble mean orography using concepts specifically developed for snow cover (Foppa et al. 2007). Calculating non-linear SWE lapse rates allowed adapting station data to be representative of the ensemble mean orography. A 3-dimensional Gaussian filter
Fig. 1 Analysis domains of this study. The dark blue area indicates the validation domain (Switzerland) whereas the light blue area encompasses the analysis domain for the climate projections. The box in the lower-right corner shows the entire European RCM domain covered by all individual RCM experiments

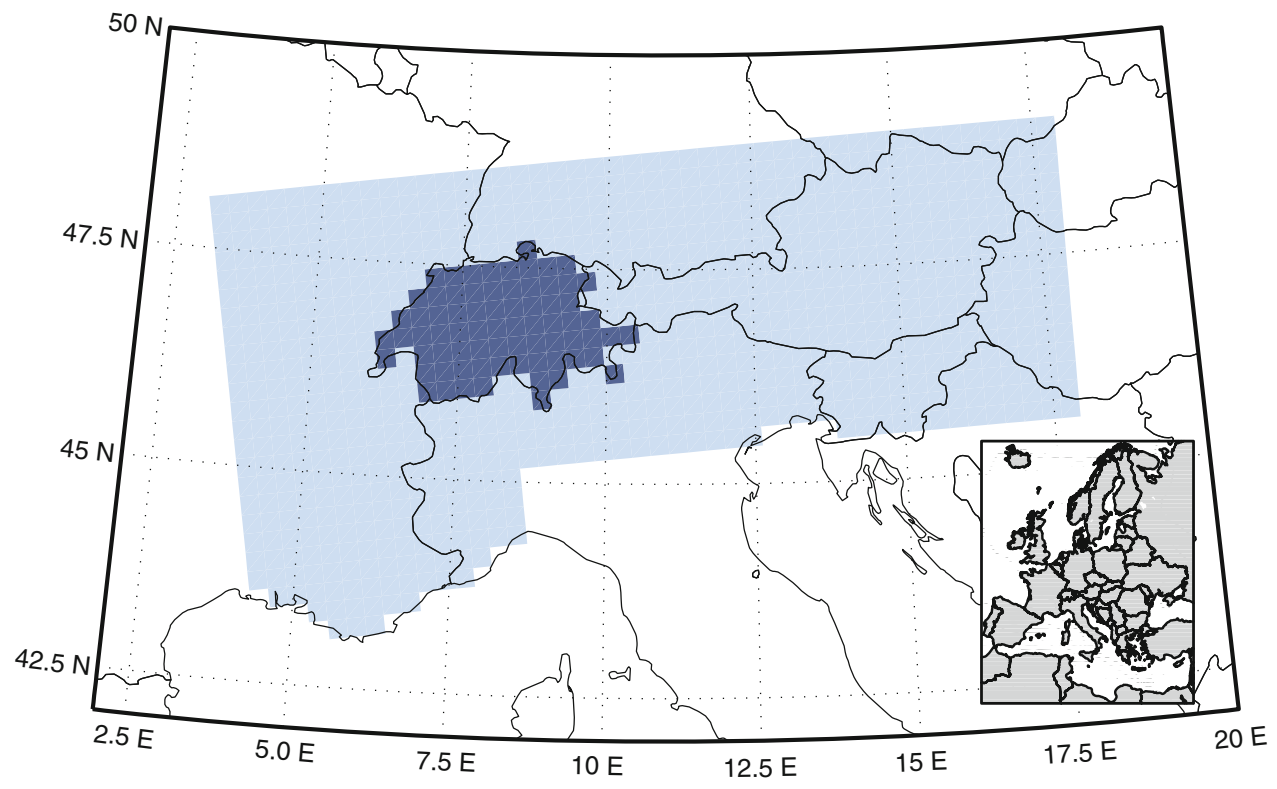




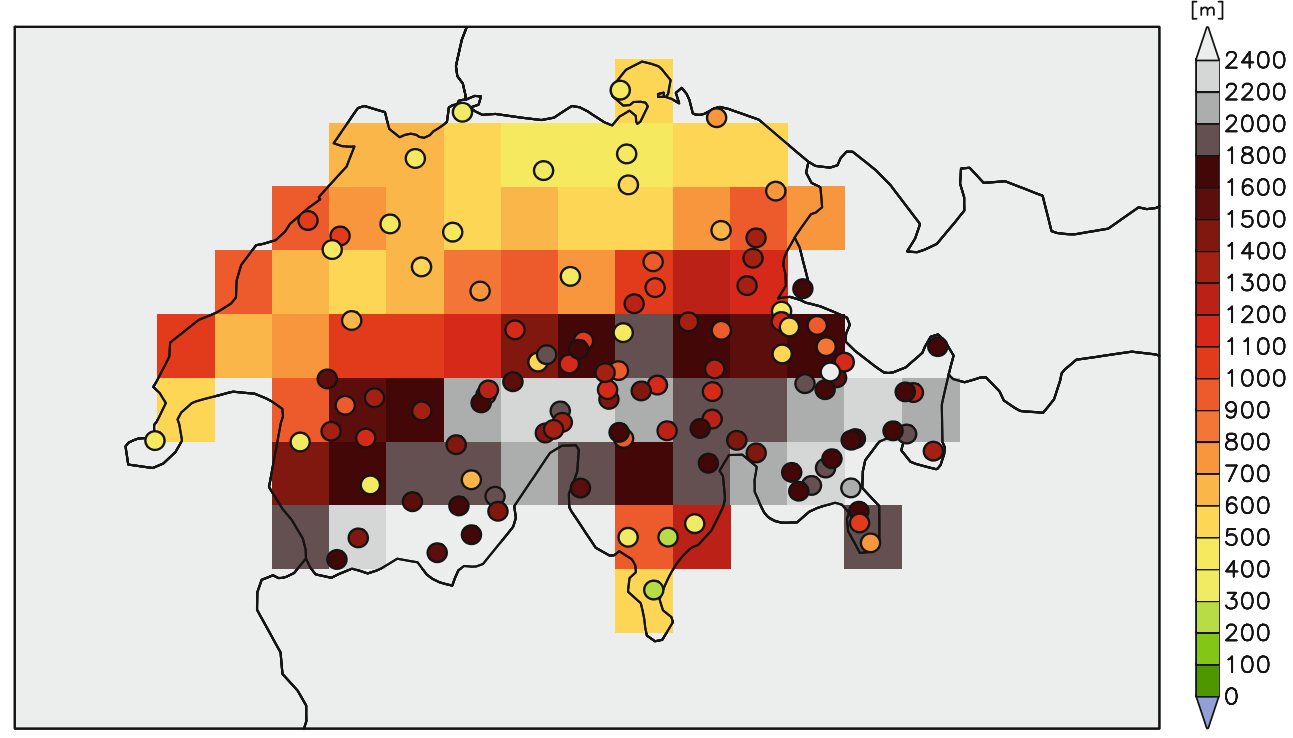

Fig. 2 Ensemble mean orography [m] of all RCMs investigated and location of the observation stations used for deriving the gridded snow water equivalent (SWE) data set. The color of the markers indicates the elevation of each individual observation station

weighting approach was used for spatial interpolation of detrended data. Given 110 stations relative to 70 grid cells, the mapping procedure is considered to allow appropriate validation, except for grid cells above $2,100 \mathrm{~m}$. The direct use of the coarse RCM ensemble mean orography for spatial interpolation is motivated by the better comparability to the simulated SWE. The coarse RCM resolution and strongly smoothed RCM orography do not account for the high spatial variability of snow distribution in complex alpine terrain and the non-linear height dependence of SWE. Averaging a high-resolution observational SWE product for each RCM grid cell would therefore make little sense. In our approach the gridded observational data represents orography-adjusted SWE values referring to the mean RCM grid cell elevation, which is ideal for comparison against the simulated SWE.

Given the restriction of the observational SWE reference data to the area of Switzerland, our model validation exercise is limited to this region and conclusions can, strictly speaking, only be drawn for the Swiss part of the Alps. However, as the topography of Switzerland covers almost the entire elevation range of the Alps and as previous studies have shown that snow cover sensitivities in Switzerland are not fundamentally different from other parts of the Alps (Hantel and Hirtl-Wielke 2007; Wielke et al. 2004) we assume that the results of our model validation are transferable to an Alpine-wide scale to some degree.

Observational data of temperature and precipitation was provided by the gridded E-OBS data set (Version 4; Haylock et al. 2008). Note that E-OBS precipitation is not corrected for systematic undercatch, known to severely affect snow precipitation measurements in mountain environments (e.g. Egli et al. 2009; Adam and Lettenmaier 2003).

\subsection{Methods}

As most of the analyzed RCMs were operated on a rotated latitude-longitude grid $\left(0.22^{\circ}\right.$, corresponding to a grid cell size of approx. $25 \mathrm{~km}$ ), all model data with other grid specifications were bilinearly interpolated onto this reference grid. Analysis of the SWE data showed that variability introduced by the horizontal distribution is rather small compared to the variability introduced by the altitude. Therefore, most of the analyses are carried out for separate altitude range classes (ARCs) rather than for different sub-regions of the analysis domain. Ensemble mean values of the RCMs are always calculated applying equal weights for all ensemble members considered (simple arithmetic mean). For model validation and as control period for the climate scenarios we're considering the period 1971-2000. The assessment of future snow cover changes is for the most part carried out for the two scenario periods 2020-2049 and 2070-2099 (subsequently called first and second scenario period) with respect to the control period. All elevation information refers to meters above sea level ( $\mathrm{m}$ asl).

An inter-model comparison of the RCM orographies yielded large differences within the Alpine region. Especially the orographies of the METO and OURANOS models show large deviations from the ensemble mean orography (Figs. ESM 2 and ESM 3). Presumably, these discrepancies have to be attributed to the use of different digital elevation models when 
computing mean grid cell orographies in the individual RCMs. For our analysis the different RCM orographies are problematic as SWE strongly depends on altitude (e.g. Schär et al. 1998) and a grid cell-by-grid cell comparison of model data and observations would be influenced by elevation differences and would not reveal a true model bias. Therefore, in the model validation part of this study, all modeled SWE data were adapted to represent the ensemble mean orography using observed monthly mean SWE lapse rates (mean values for Switzerland). Due to the temporal and spatial limitations in the availability of the observational data, the validation could only be carried out for the winter months December to April and for elevations below $2,100 \mathrm{~m}$. Grid cells with elevations above $2,100 \mathrm{~m}$ in either the individual RCMs or in the ensemble mean orography were excluded from the validation exercise. The three ARCs defined for the validation part encompass regions below $1,000 \mathrm{~m}$, between 1,000 and $1,500 \mathrm{~m}$ and between 1,500 and $2,100 \mathrm{~m}$.

An in-depth analysis of the GCM-driven RCMs revealed snow accumulation deficiencies in some models (DMIECHAM5, DMI-BCM, METNO-BCM, METNO-HadCM3Q0 and UCLM-HadCM3Q0) with constantly accumulating SWE (i.e. ongoing glaciation) at altitudes above $2,000 \mathrm{~m}$. Such elevations are mostly far below today's equilibrium line altitudes in the Alps (e.g. Zemp et al. 2007) and these models have to be considered as strongly biased regarding their representation of high-elevation SWE. They were therefore excluded from the analysis at elevations above $2,000 \mathrm{~m}$. In contrast to the validation part, the winter season considered for the climate projections encompasses the months November to April and five (instead of three) ARCs are defined. The two lowest ARCs are identical to the ones used for the validation part whereas the three higher ARCs encompass elevations from 1,500 to $2,000 \mathrm{~m}, 2,000$ to $2,500 \mathrm{~m}$ and elevations above $2,500 \mathrm{~m}$. Note that ARC 5 encompasses only very few grid cells in some RCMs and that its geographical location within the analysis domain can differ considerably between the models; the inter-model comparison in this ARC has therefore to be interpreted with care. The duration of continuous snow cover was calculated by searching the begin and the end of the longest succession of days with a minimum SWE value of $2 \mathrm{~cm}$ for each year, each grid cell and each model, before averaging over time (30 years) and over elevation classes. Similarly, the timing of peak SWE was determined for each individual year and grid cell before averaging over time and elevation. A non-parametric Wilcoxon rank sum test was used to test for significant (0.05 level) changes in snow cover variables between the current and future periods (Sect. 4.3). Linear trends in mean winter SWE were computed by least-squares regression (Sect. 3.3).

In the climate projection part, we also analyzed the socalled hundred-days rule. According to this rule, a typical
Swiss ski-region is snow reliable (for alpine skiing) in winters with a minimum of 100 days of snow depth larger than $30 \mathrm{~cm}$ between the first of December and the fifteenth of April (Abegg 1996). A useful addition is the definition of a second threshold of $50 \mathrm{~cm}$ for elevations above 1,500 to $2,000 \mathrm{~m}$. At these elevations, the terrain often features a higher roughness and therefore larger amounts of snow are needed for slope preparation. Analysis of the financial situation of cable-car companies furthermore revealed that 7 out of 10 winters have to be snow reliable to operate a ski-region profitably (Buerki 2000). The application of the hundred-days rule with these two extensions (in the following simply referred to as hundred-days rule) required the de-biasing of the RCM data. The climate projection SWE data was therefore bias-corrected applying monthly mean correction factors that were obtained by a comparison against observations in the period 1971-2000 for $500 \mathrm{~m}$ elevation bands. The correction factors were then applied for the entire scenario period until 2099, implicitly assuming an SWE model bias that is constant in time. In a second step the SWE-values were converted to snow depth assuming elevation dependent mean snow densities for each day of the year based on Jonas et al. (2009), i.e. based on the same snow density model that was used for constructing the gridded observational SWE dataset (see above). Finally, snow depths were averaged over $200 \mathrm{~m}$ elevation bins for each individual model and the number of models that indicate a fulfillment of the hundred-days rule was counted for each elevation bin and each decade. Altogether, 11 RCM scenarios were considered (those extending until 2099 and not showing accumulation issues).

\section{Validation}

\subsection{Mean winter SWE}

The basic spatial pattern of observed mean winter SWE in Switzerland is captured by all ERA40-driven RCMs with small values in the northern and extreme southern parts and a considerably higher mean winter SWE along the Alpine ridge (Fig. ESM 4). Most experiments also share a similar bias pattern of mean winter SWE. In the lowest ARC, SWE is considerably underestimated (ensemble mean $-32 \%$; Table 2 and Fig. 3). Only the EC and the OURANOS models reveal a positive bias. In ARC 2, ranging from 1,000 to $1,500 \mathrm{~m}$, the majority of models underestimate SWE but with smaller relative biases (ensemble mean $-12 \%)$. In the highest ARC most models overestimate SWE (ensemble mean $+9 \%$ ), in particular the METO models show a strong overestimation. The CNRM, DMI and MPI models underestimate SWE in all ARCs while the 
Table 2 Deviation of the simulated mean winter (DJFMA) SWE for the period 1971-2000 from the observed values

\begin{tabular}{|c|c|c|c|c|c|c|c|}
\hline \multirow[t]{2}{*}{ Institute-model } & \multicolumn{3}{|c|}{ ERA40-driven } & \multicolumn{4}{|l|}{ GCM-driven } \\
\hline & ARC $1(\%)$ & ARC $2(\%)$ & ARC $3(\%)$ & GCM & ARC $1(\%)$ & ARC $2(\%)$ & ARC $3(\%)$ \\
\hline C4I-RCA3 & -70 & -34 & +34 & HadCM3Q16 & -81 & -42 & +48 \\
\hline CNRM-Aladin & -61 & -74 & -55 & ARPEGE & -10 & -20 & +18 \\
\hline \multirow[t]{3}{*}{ DMI-HIRHAM } & -77 & -63 & -85 & ARPEGE & -87 & -74 & -18 \\
\hline & & & & $\mathrm{BCM}$ & +47 & +136 & +148 \\
\hline & & & & ECHAM 5 & -15 & +109 & +215 \\
\hline EC-GEMLAM & +39 & +97 & +37 & & & & \\
\hline ETHZ-CLM & -28 & -51 & +7 & HadCM3Q0 & +17 & -30 & +33 \\
\hline KNMI-RACMO & -58 & -26 & +14 & ECHAM5 & -69 & -23 & +62 \\
\hline \multirow[t]{2}{*}{ METNO-HIRHAM } & -46 & -47 & -16 & $\mathrm{BCM}$ & +136 & +106 & +30 \\
\hline & & & & HadCM3Q0 & +7 & -4 & -5 \\
\hline METO-HadRM3Q0 & -35 & +59 & +71 & HadCM3Q0 & -24 & +66 & +77 \\
\hline METO-HadRM3Q3 & -44 & +60 & +73 & HadCM3Q3 & -20 & +36 & +34 \\
\hline METO-HadRM3Q16 & -63 & -7 & +56 & HadCM3Q16 & -69 & +3 & +71 \\
\hline MPI-REMO & -70 & -60 & -44 & ECHAM5 & -76 & -62 & -24 \\
\hline OURANOS-CRCM & +196 & +21 & +2 & CGCM3 & +372 & +57 & +15 \\
\hline \multirow[t]{3}{*}{ SMHI-RCA } & -61 & -23 & +39 & $\mathrm{BCM}$ & -77 & -45 & +63 \\
\hline & & & & ECHAM5 & -79 & -41 & +60 \\
\hline & & & & HadCM3Q3 & -37 & -27 & +26 \\
\hline UCLM-PROMES & -71 & -25 & -5 & HadCM3Q0 & -41 & +90 & +290 \\
\hline Ens. mean & -32 & -12 & +9 & & -6 & +13 & +64 \\
\hline
\end{tabular}

The altitude range classes (ARCs) are arranged in ascending order; i. e. ARC $1(<1,000 \mathrm{~m})$, ARC $2(1,000-1,500 \mathrm{~m})$, ARC $3(1,500-2,100 \mathrm{~m})$
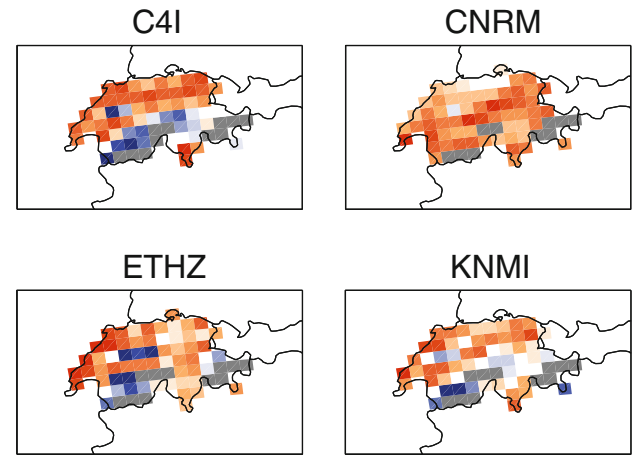

METO Q3
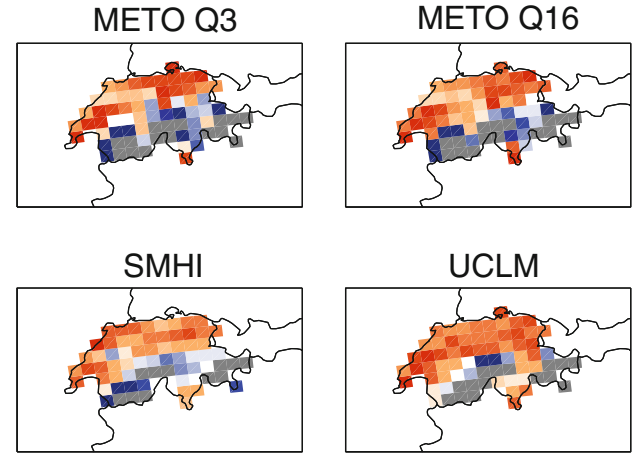

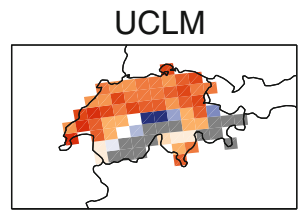

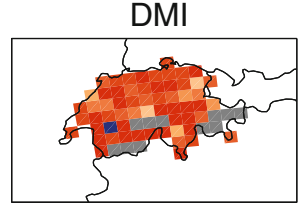
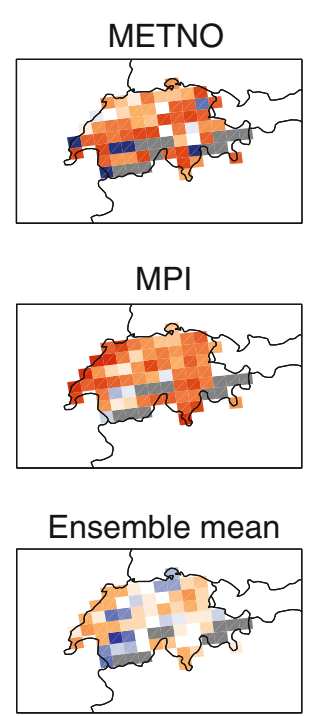

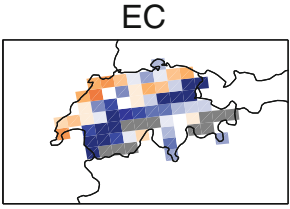

[\%]
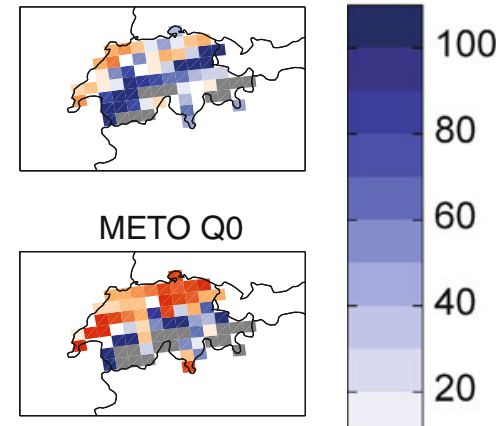

60

40

20
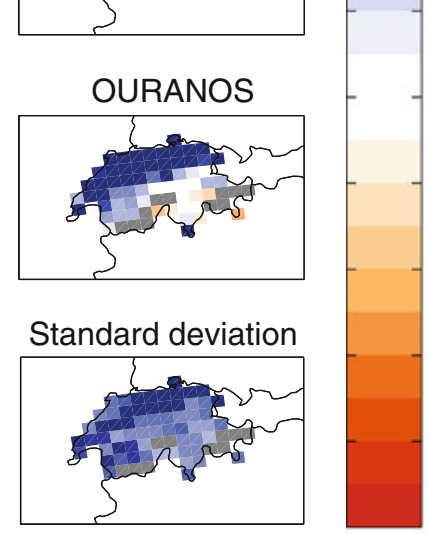

Fig. 3 Mean winter SWE bias [\%] in the ERA40-driven RCMs in the period 1971-2000. The lower right panel shows the standard deviation of the individual RCM biases, normalized by the observed mean SWE. Gray color indicates grid cells with elevations above
$2,100 \mathrm{~m}$ in either the individual RCMs or in the ensemble mean orography. These cells were excluded from the model evaluation as reliable observational data are not available 

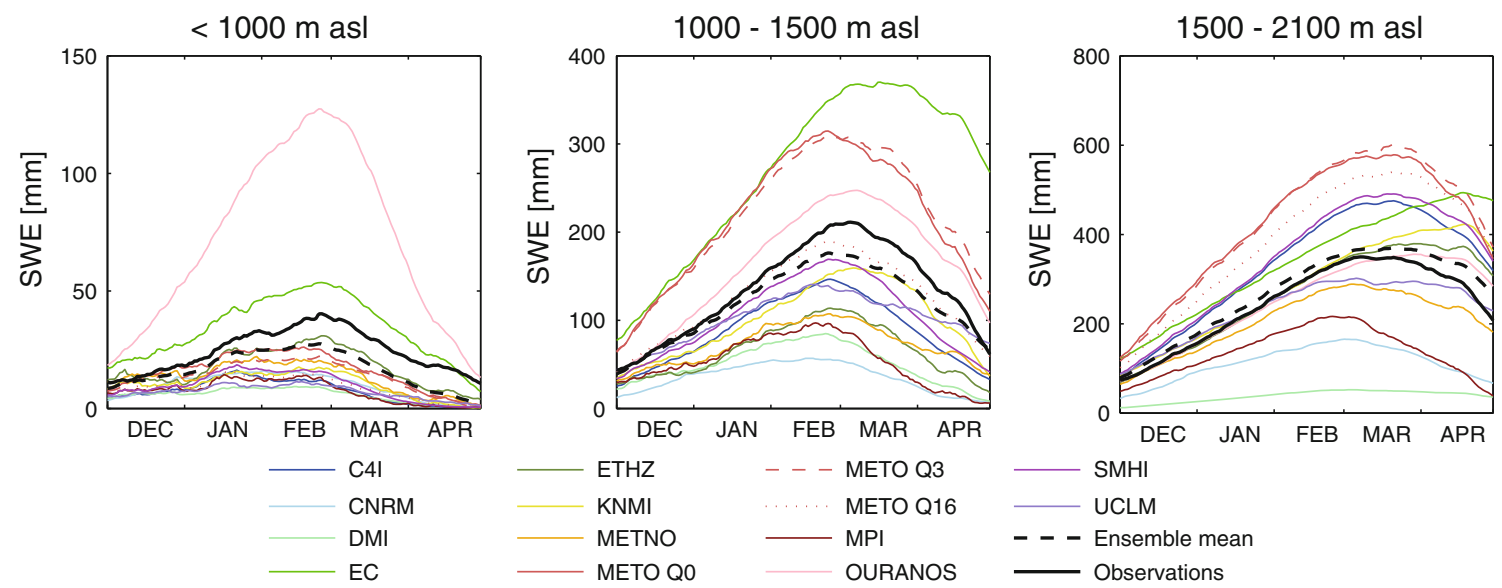

Fig. 4 Mean seasonal SWE evolution [mm] during winter in the ERA40-driven RCMs and in the observations averaged over the years 1971-2000. The bold dashed line indicates the ensemble mean. Note the different $y$ axis scale of the three panels

contrary is true for EC and OURANOS. The latter model is an exceptional case in the ensemble since it overestimates mean winter SWE in all ARCs, but the overestimation is strongest at low elevations and becomes almost negligible with increasing altitude. The very strong SWE overestimation of the OURANOS model in the low-lying northern parts of Switzerland counterbalances the negative bias of most other models, yielding a rather accurate representation of mean winter SWE in the ensemble mean (Fig. 3). This effect of compensating errors is also indicated by the large standard deviation of the individual model biases in the northern parts (lower right panel in Fig. 3).
The GCM-driven RCMs have a similar spatial SWE distribution and a similar elevation-dependent bias as the ERA40-driven models with a general shift towards higher SWE values in all ARCs (Table 2 and Figs. ESM 5 and ESM 6). The ensemble mean SWE biases for the three ARCs in ascending order amount to $-6,+13$ and $+64 \%$, respectively. The relative bias of the OURANOS model is positive in all ARCs with an even higher magnitude as in case of the reanalysis-driven experiment. At low elevations this leads to a high standard deviation of the individual model biases and, again, to compensating effects in the ensemble mean (Fig. ESM 6, lower right panels). Only

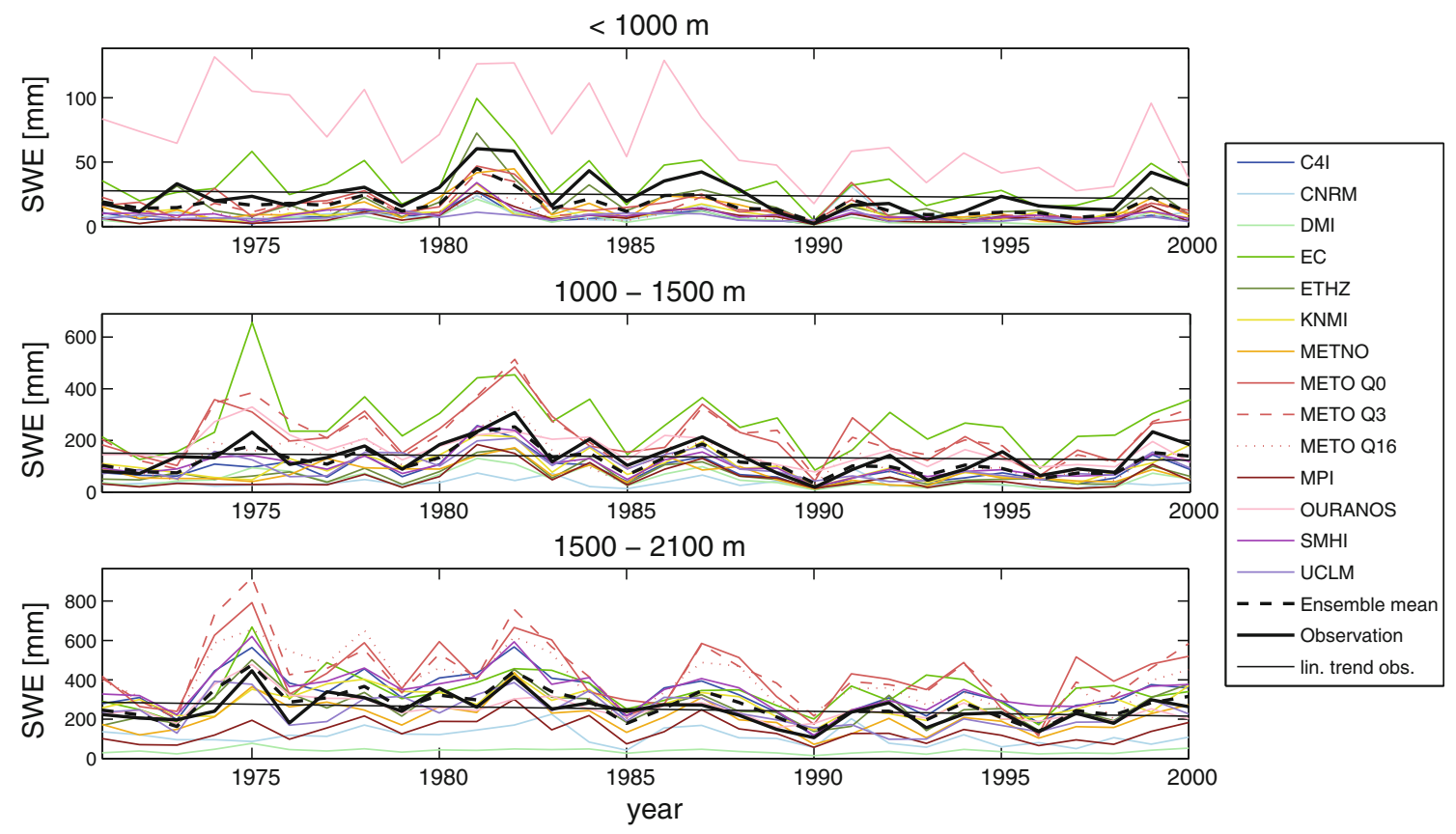

Fig. 5 Evolution of mean winter SWE [mm] in the period 1971-2000 in the ERA40-driven RCMs and in the observations for three ARCs (upper panel $<1,000 \mathrm{~m}$, middle panel 1,000-1,500 m, lower panel 1,500-2,100 m). The bold dashed line indicates the RCM ensemble mean SWE, the thin black line shows the linear SWE trend in the observations based on least-squares regression 
MPI-ECHAM5 and DMI-ARPEGE underestimate mean winter SWE in all ARCs. RCMs with the same GCM as driver show a high inter-model variability (Fig. ESM 6), indicating that SWE biases cannot be explained by inaccuracies of the driving GCM data alone.

\subsection{Seasonal evolution of SWE}

The seasonal SWE analysis of the ERA40-driven RCMs shows that the general course of the SWE evolution throughout the winter-including the timing of maximum SWE-is overall well represented but that substantial model biases can occur (Fig. 4). At elevations below 1,000 m peak SWE mostly occurs too early. The absolute model spread is increasing with altitude. In the highest ARC some RCMs show a maximum SWE that occurs too late in the season. For instance, the EC model reaches its maximum SWE in April whereas the observational SWE peaks in early March. Most models underestimate SWE for most parts of the winter season in the middle as well as in the lower ARC. In contrast, the OURANOS model has a very strong positive SWE bias at low elevations throughout the entire winter season, which is connected to a pronounced cold bias of this model (see Sect. 3.4). These findings are consistent with the analysis of mean winter SWE in the previous subsection. Again, the ensemble mean SWE is very close to the observations in all ARCs as the individual model biases partly cancel each other out. Concerning the duration of continuous snow cover in the ERA40-driven RCMs, the snow season is too short in the lowest ARC for all RCMs except for the OURANOS model (not shown). A validation of the continuous snow cover duration in the higher ARCs is not possible as the observation data is limited to the period December to April.

In the GCM-driven experiments, the ensemble mean matches the seasonal evolution of the observed SWE quite accurately in the two lower ARCs (Fig. ESM 7). In the highest ARC the positive SWE bias increases with time and reaches its maximum in late winter. The inter-model range for the two lower ARCs is higher than in case of the ERA40-driven RCMs, which partly reflects the differing driving GCMs. In the highest ARC, the majority of models reaches peak SWE too late in the season.

\subsection{Interannual variability and trend}

The temporal evolution of simulated and observed mean winter SWE for ARCs 1, 2 and 3 in the period 1971-2000 is shown in Fig. 5. The relating statistics (temporal correlation coefficient, temporal standard deviation, linear trend) are given in (Table 1 of the ESM). The general temporal variability of observed mean winter SWE is well captured by most RCMs with correlation coefficients typically exceeding a value of 0.7. Also the ensemble mean winter SWE strongly correlates with the observations (temporal correlation coefficients of $0.84,0.89$ and 0.84 for ARC 1,2 and 3 , respectively). Only CNRM shows a rather weak temporal correlation with the observed SWE time series (correlation coefficients smaller than 0.29), indicating a deficient translation of the large-scale atmospheric forcing provided by the ERA40 re-analysis into Alpine snow cover variability in this particular model. There is no apparent relation between the magnitude of the relative mean winter SWE bias (Table 2) and the temporal correlation coefficient with observations, i.e. models with a strong over- or underestimation of mean winter SWE can still correlate well with the observations on an interannual scale. Concerning the temporal standard deviation, most models capture the magnitude of interannual SWE variability and also the general increase of the absolute standard deviation with elevation (middle section of Table 1 in the ESM). This is also true for the ensemble mean SWE. Observed linear winter SWE trends are negative in all elevation classes (right section of Table 1 in the ESM), a feature that is reproduced by most RCM experiments. The absolute magnitude of the linear trends, however, considerably varies between the models but, in accordance with observations, typically increases with increasing elevation (stronger absolute loss of mean winter SWE at high elevations). The observed SWE trend is underestimated by the ensemble mean SWE in all elevation classes (i.e. stronger decline of ensemble mean SWE than of observed SWE) but the general magnitude of the trend is captured. It has to be noted though that absolute SWE trends are strongly influenced by the overall SWE bias: Models with a strong overestimation (underestimation) of mean winter SWE typically show a pronounced overestimation (underestimation) of the absolute mean winter SWE loss in the period 1971-2000. The same holds for the relation between the mean SWE model bias and the temporal standard deviation.

\subsection{Discussion}

The model evaluation presented above shows that state-ofthe-art RCMs are able to capture the general snow cover characteristics in a region of high topographic variability such as Switzerland. This is true for both the ERA40driven and the GCM-driven experiments. The spatial variability of mean winter SWE is well represented in most models (Figs. ESM 4 and ESM 5) and also the shape of the mean seasonal SWE evolution at different elevations (Fig. 4 and Fig. ESM 7). In the ERA40-driven experiments peak SWE below 1,000 m mostly occurs too early but is rather well captured at higher elevations. Partly due to compensating biases, the multi-RCM ensemble mean 
accurately represents mean winter SWE at elevations below 1,500 $\mathrm{m}$ (biases between -32 and $+13 \%$ ). The interannual variability of observed mean winter SWE is well captured by the ERA40-driven experiments with correlation coefficients typically exceeding a value of 0.7 (Table 1 of the ESM).

However, both the ERA40- as well as the GCM-driven RCMs have difficulties in simulating the observed SWE lapse rates. The simulated SWE values at low elevations are generally too small whereas the models tend to overestimate snow at higher elevations (Fig. 3 and Fig. ESM 6). Additional supporting figures in the ESM allow to relate these SWE biases to biases in the atmospheric forcing (Figs. ESM 8 and ESM 9) and provide additional insight into the responsible processes by a separate analysis of snow accumulation and snow ablation (Fig. ESM 10). The reasons for the positive SWE biases in the two higher ARCs are probably linked to the pronounced overestimation of precipitation at these elevations (Figs. ESM 8 and ESM 9, right columns). In a number of RCMs, particularly in the METO models, this results in an overestimation of the mean daily accumulation rate (Fig. ESM 10, lower left panel). CNRM and DMI considerably underestimate the mean accumulation rate in all ARCs and, consequently, show a strong negative SWE bias at all elevations. Please note that precipitation biases have to be interpreted carefully as the observational values are not corrected for the systematic measurement error of rain gauges. This error is especially large at high elevations that encounter higher wind speeds and a higher fraction of solid precipitation compared to lower elevations (Adam and Lettenmaier 2003). The annual correction values for precipitation in Switzerland are in the range of 5-25\%, depending on region and altitude (Sevruk 1997). The contribution of the distinctive negative temperature bias in higher elevations (Figs. ESM 8 and ESM 9, left column) to the overestimation of SWE is probably limited to early and late winter where the observed temperature is near the freezing point and a cold model bias leads to an overestimation of the snowfall fraction and, correspondingly, of snow accumulation. This overestimation of snow mass is, however, carried on through the season and also affects mid-winter peak SWE. In the investigated winter period DecemberApril the high-elevation cold bias has only little effect on the number of accumulation days which are accurately captured by the models (Fig. ESM 10, upper left panel).

The underestimation of SWE in the lowest ARC is not readily explainable by considering temperature and precipitation biases alone and would require a more detailed analysis with the inclusion of further variables relevant for snow cover. It seems, however, to be connected to an underestimation of the mean daily accumulation rate while the length of the accumulation period is rather well captured by the models (Fig. ESM 10, left panels). As regions below $1,000 \mathrm{~m}$ represent approximately half of Switzerland's surface area, the negative SWE bias at these elevations might be especially relevant for the snow albedo feedback. The overestimation of SWE in the OURANOS model, which is strongest at elevations below $1,000 \mathrm{~m}$, is in line with the strong cold bias of several degrees Celsius at all elevations and throughout the entire winter (Figs. ESM 8 and ESM 9, left column). This cold bias leads to a considerable overestimation of the number of accumulation days at all elevations (Fig. ESM 10, upper left panel). Regarding the influence of the large-scale circulation on Alpine snow cover, the good agreement between the temporal patterns of observed and simulated mean winter SWE (ERA40-driven RCMs) indicates that (1) winter snow cover in the European Alps is strongly conditioned by the prevailing large-scale circulation (which is imposed onto the RCMs by the ERA40 re-analysis at the lateral boundaries) and that (2) most RCMs are capable of translating temporal variabilities in the imposed boundary forcing rather accurately into Alpine snow cover variability.

A comparison of regional temperature and precipitation biases in the ERA40- and GCM-driven RCMs in the three ARCs yields similar results for temperature but larger positive precipitation biases in the GCM-driven RCMs. These larger amounts of precipitation are likely to be responsible for the larger amounts of SWE in the GCM-driven RCMs. Another apparent feature is the larger inter-model spread of temperature and precipitation in the GCM-driven experiments which can be explained by the different boundary forcing of the individual experiments (compared to an identical boundary forcing in case of the ERA40-driven runs). For the GCM-driven experiments an important influence of the driving GCM on the temperature bias can be identified which, however, is typically associated with different bias characteristics of SWE (color scheme in Figs. ESM 7 and ESM 9). This again indicates that SWE biases cannot be explained by temperature biases alone and that at least precipitation biases (which are less consistent among experiments with identical boundary forcing; right panels in Fig. ESM 9) have to be taken into account. Indeed, the seasonal evolution of simulated SWE in combination with simulated temperature and precipitation indicates two obvious features at elevations above 1,000 m: Firstly, the monthly mean temperature in early winter is below zero degrees for all experiments (ERA40and GCM-driven). This suggests that the snow accumulation rate in the RCMs is primarily a matter of precipitation (although temperature variations can certainly have an influence and rainfall/snowmelt can still occur in months with mean temperatures below zero). Accordingly, models 
with highest precipitation biases typically have the highest SWE accumulation rate and vice versa (Fig. 4, right columns of Figs. ESM 7, ESM 8 and ESM 9, Fig. ESM 10). Secondly, snow melt in late winter is mostly a matter of temperature. Hence the delayed start of snow melting may partially be related to the cold temperature biases of some models. These simple considerations cannot be made for elevations below $1,000 \mathrm{~m}$ where both temperature and precipitation (as well as biases thereof) have a strong influence on simulated snow cover over the entire winter season.

A validation of a similar set of GCM-driven RCMs for mean March SWE in Finland by Räisänen and Eklund (2012) revealed a better agreement between simulated absolute values and interpolated observations. A possible reason for the larger SWE biases in our study is the more complex orography of the analysis domain that is only partially resolved by the horizontal resolution of the RCMs. Indeed, studies that coupled high resolving land-surfacemodels to RCM output generally reached better agreements between simulated and observed snow parameters (Bavay et al. 2009; Magnusson et al. 2010).

\section{Climate projections}

\subsection{Mean winter SWE change}

Figure 6 presents the temporal evolution of mean winter SWE changes in the European Alps for all GCM-driven model experiments and for all ARCs relative to control conditions (1971-2000). Relative SWE changes in the lowest ARC are strongest during the first half of the twenty first century and show a reduction of about $-70 \%$ by the end of the century (ensemble mean). The higher ARCs show a more constant rate of SWE reduction throughout the twenty first century and an increase in inter-model spread with time. The relative reduction of SWE becomes smaller with altitude and amounts to about $-60 \%$ $(1,500-2,000 \mathrm{~m}), \quad-50 \%(2,000-2,500 \mathrm{~m})$ and $-40 \%$ (above $2,500 \mathrm{~m}$ ) for the ensemble mean by the end of the century. The only RCMs that show a notable positive change in mean winter SWE are some ECHAM5-driven models in the lowest ARC at the beginning of the twenty first century and two of the METO experiments in the highest ARC until the middle of the twenty first century. These findings are in line with the horizontal distribution of mean winter SWE changes in the individual experiments (Figs. ESM 12 and ESM 13). The special behavior of the DMI-ARPEGE model, which shows a pronounced percentage increase of SWE during the second half of the century in the lower ARCs, is caused by four snow-rich winters in the late 2060s, early 2070s and early 2090s (not shown) combined with a very small mean winter SWE at low elevations in the control period (compare to Figs. ESM 6 and ESM 7). The coloring scheme in Fig. 6 allows to assess the influence of the driving GCM on the modeling results. In many cases the simulated SWE change strongly depends on the driving GCM, indicating a considerable influence of large-scale temperature and humidity changes inherited from the boundary forcing (e.g. ECHAM5- and HadCM3-driven simulations in the four lower ARCs).

\subsection{Change of the seasonal SWE evolution}

The inter-model spread of mean daily SWE for the control period and the two scenario periods is decreasing in most of the ARCs with time (shaded areas in Fig. 7). The decrease in absolute SWE in the lowest ARC is stronger from the control to the first period than from the first to the second period. This relation is reversed with increasing elevation. Another notable feature in Fig. 7 is the asymmetrical shape of the curves in the two higher ARCs, indicating that accumulation in early winter is slower than melting in late winter and spring. The evolution of the ensemble mean SWE course (solid lines in Fig. 7) suggests a shift of the occurrence of maximum SWE in the higher ARCs to earlier times in the winter. This is consistent with the elevation and latitude dependence of present-day maximum SWE (earlier occurrence in warmer settings, where the spring snow melt occurs earlier). The temporal shift of peak SWE together with the shift of the beginning and the end of the continuous snow cover season is displayed in Fig. 8 and in Figure ESM 14. The analysis indicates similar qualitative changes for all ARCs. Note that the lowest ARC $(<1,000 \mathrm{~m})$ is not shown as the threshold of $2 \mathrm{~cm}$ SWE is only rarely exceeded and a continuous snow cover period can hardly be defined. For most ARCs and for most models, peak SWE occurs by about half a month to one month earlier in the second scenario period compared to the control climate. For all elevations and models the analysis reveals a shortening of the snow cover season. This shortening is asymmetrical with a stronger reduction occurring in spring. The shortening in the ensemble mean is 24 days for the first scenario period and 53 days for the second period in the ARC from 1,000 to $1,500 \mathrm{~m}$. In the higher ARCs the reduction is even more pronounced with a shortening in the ensemble mean by 28-32 days for the first scenario period and by more than 75 days for the second period.

\subsection{Significance of snow cover changes}

Figure 9 provides an overview on the sign and the statistical significance of changes of several snow cover parameters. The inter-model agreement on the significant 
(a) $<1000 \mathrm{~m}$ asl

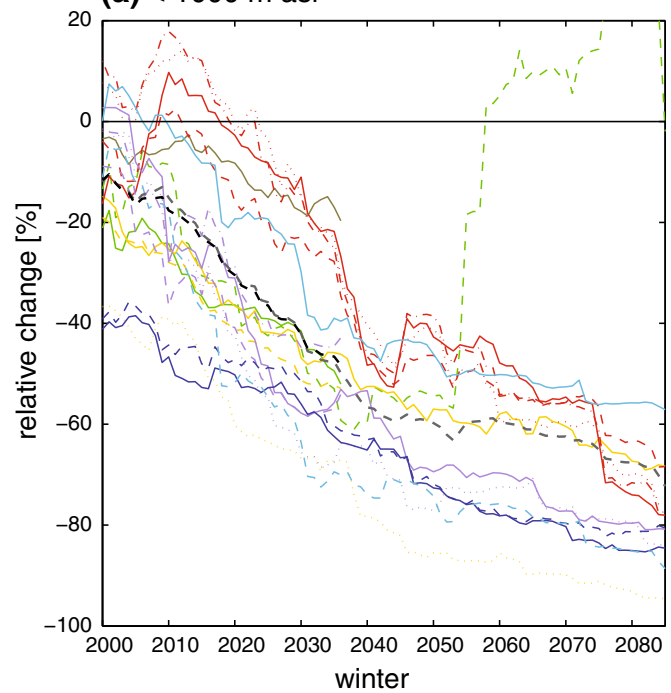

(c) $1500-2000 \mathrm{~m}$ asl

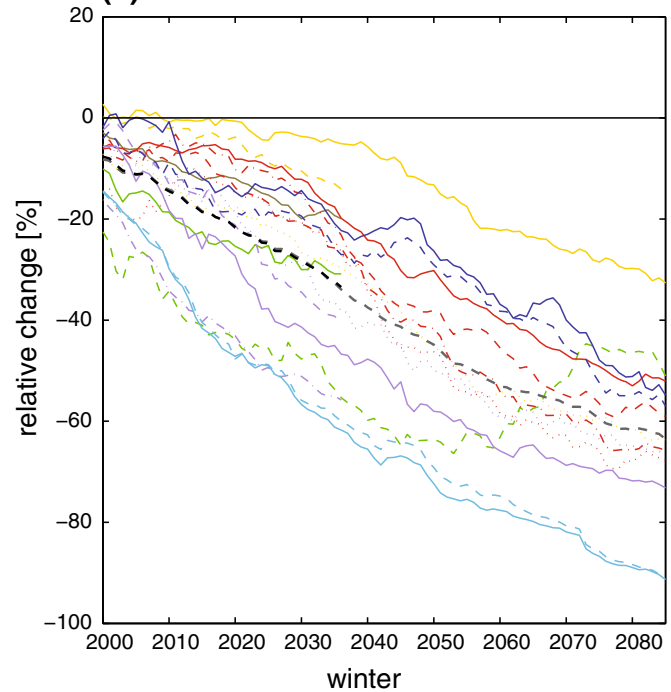

(e) $>2500 \mathrm{~m}$ asl

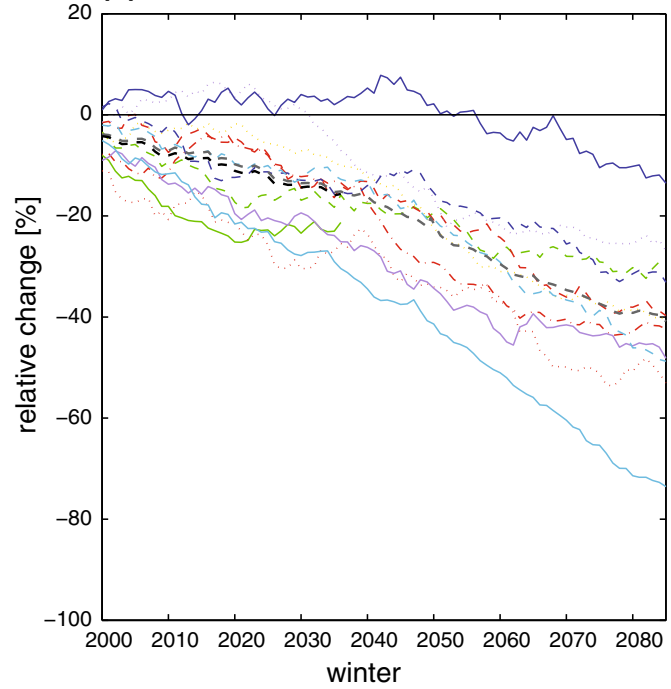

(b) $1000-1500 \mathrm{~m}$ asl

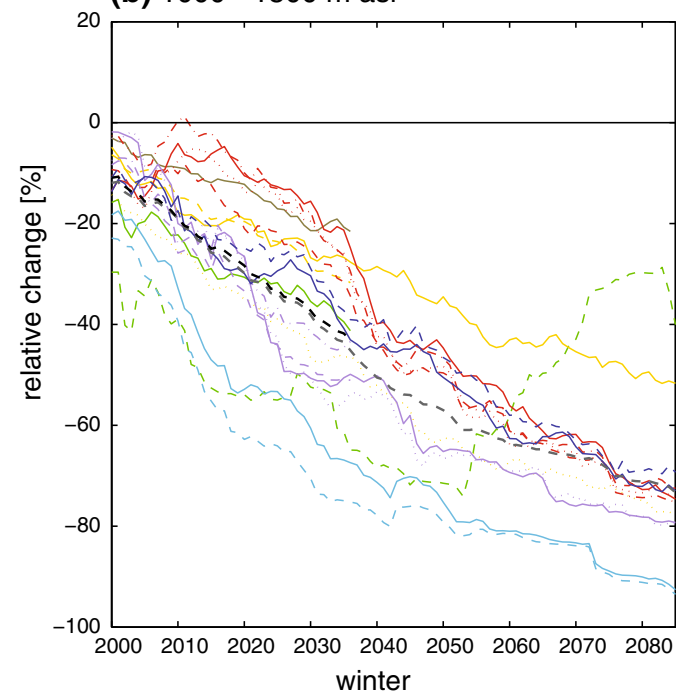

(d) $2000-2500 \mathrm{~m}$ asl

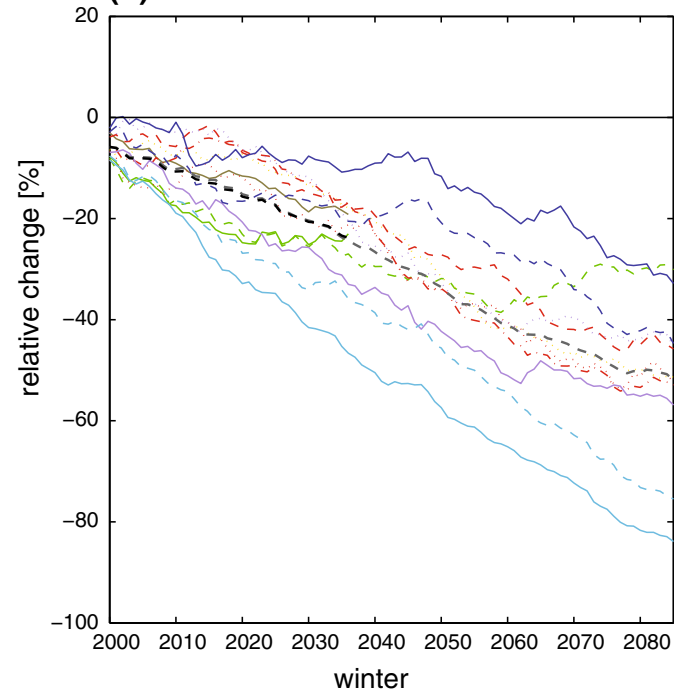


4 Fig. 6 Change of mean winter SWE in the GCM-driven experiments relative to 1971-2000 [\%]. The data is filtered by a 30-year running mean. Note that some experiments stop in the year 2050. Accordingly, two ensemble mean curves are provided [one including the full set of experiments until 2050 (black), one including only those experiments that are available until 2099 (grey)]. The experiments are colored according to the driving GCM

negative change in mean SWE (upper left panel) is very high, especially for the second scenario period. At all elevations more than $90 \%$ of the models indicate a significant decrease of mean winter SWE. Most models also agree on the sign of changes for the parameters related to the seasonal evolution of snow cover. For the start of continuous snow cover (upper right panel) all models indicate a positive temporal shift, i.e. an onset of snow cover later in the season. In the second scenario period this shift is mostly significant. Similarly, the end of the snow cover season is significantly shifted to earlier times in the year in all models by 2070-2099 (lower right panel). For peak SWE (lower left panel) between 30 and $70 \%$ of the models show a significant shift to earlier times in the year for the first the scenario period. By 2070-2099 the earlier occurrence of maximum SWE is significant in almost all experiments.

\subsection{Hundred-days rule}

The application of the hundred-days rule onto the RCM output (Fig. 10) shows that snow reliability in the Alps is steadily decreasing in the course of the twenty first century. The elevation of snow reliability for a snow depth threshold of $0.3 \mathrm{~m}$ for today's climate (beginning of the twenty first century; upper panel) depends on the individual RCMs and varies between 1,100 and $1,900 \mathrm{~m}$. This is in approximate agreement with previous observation-based studies that found a fulfillment of this rule between 1,050 and 1,500 m, depending on the region (Abegg et al. 2007). For the decade 2000-2009 more than 50\% of the models indicate snow reliability up from $1,400 \mathrm{~m}$. During the twenty first century this critical elevation rises to $1,800 \mathrm{~m}$ by mid century and to more than 2,000 $\mathrm{m}$ by the end of the century. For the decade 2090-2099 less than $10 \%$ of the models indicate snow reliability at altitudes below 2,000 $\mathrm{m}$. However, at high elevations between 2,000 and $2,600 \mathrm{~m}$, a majority of the models still indicates sufficient amounts of snow. A more pessimistic projection is obtained for the snow depth threshold of $0.5 \mathrm{~m}$ (lower panel). Up from the 2080s snowreliable conditions are found at elevations above $2,200 \mathrm{~m}$ only, and only in about $50 \%$ of the models.

\subsection{Discussion}

Our analysis of future snow cover changes in the GCMdriven $\mathrm{RCM}$ ensemble reveals pronounced reductions of both mean winter SWE and the length of the snow season at all elevations. It should, however, be stressed that the derived changes in snow parameters (especially absolute changes) have to be interpreted with care as the validation of the GCM-driven RCMs indicated considerable biases in ensemble mean SWE with a general underestimation of SWE in regions below $1,000 \mathrm{~m}$ and an overestimation above. Still, a comparison with previous studies in which alpine snow cover was simulated with high-resolution land surface models reveals results that are mostly in line with our own findings: The reduction of mean SWE by the end of the twenty first century amounts to -40 to $-70 \%$ (depending on elevation) which is similar to projected snow volume reductions in Switzerland reported by Beniston et al. (2003). Another finding of the latter study is the asymmetrical shortening of the snow season that concerns more the end than the beginning - a result that is confirmed by our analysis. Previous studies focusing on subareas of Switzerland and applying more complex snowpack models suggested that snow cover duration will shorten by about one month at the beginning and one and a half month at the end (Bavay et al. 2009; Magnusson et al. 2010)—similar values for the shortening were obtained in our study.

A comparison of the changes in snow reliability with previous studies is difficult as these studies were mostly carried out for specific ski areas. Steiger (2010) found that under the A1B emission scenario three ski areas in Austria with mean elevations ranging from 1,100 to $1,900 \mathrm{~m}$ will lose their natural snow reliability by the end of the twenty first century. This finding is in approximate agreement with the results of our study. Steiger (2010) also stress that the snow reliability of a ski area strongly depends on the local climate conditions. Such local features as well as local topographic effects are important factors in the evaluation of snow reliability and are only approximately or not at all resolved by an RCM. Also potential benefits from artificial snow making (e.g. Scott et al. 2003; Scott and McBoyle 2007) are not considered in our study. Hence, Fig. 10 only shows a general and spatially averaged picture and its applicability to individual ski areas is limited. Nevertheless the direct evaluation of an RCM has various advantages compared to the use of high-resolution land surface models as discussed in the introduction.

The reason for the asymmetric shortening of the snow cover season is probably related to the different processes relevant for changes in the seasonal course of SWE. In autumn and early winter the dominant process is accumulation of snow by snowfall; this process is primarily influenced by solid precipitation and any snowfall decrease will generally result in a later onset of snow cover. Also temperature plays a role since conditions have to be cold enough for fallen snow to remain on the ground. In spring, the dominant factor is ablation that is (besides radiation) 
(a) $<1000 \mathrm{~m}$ asl

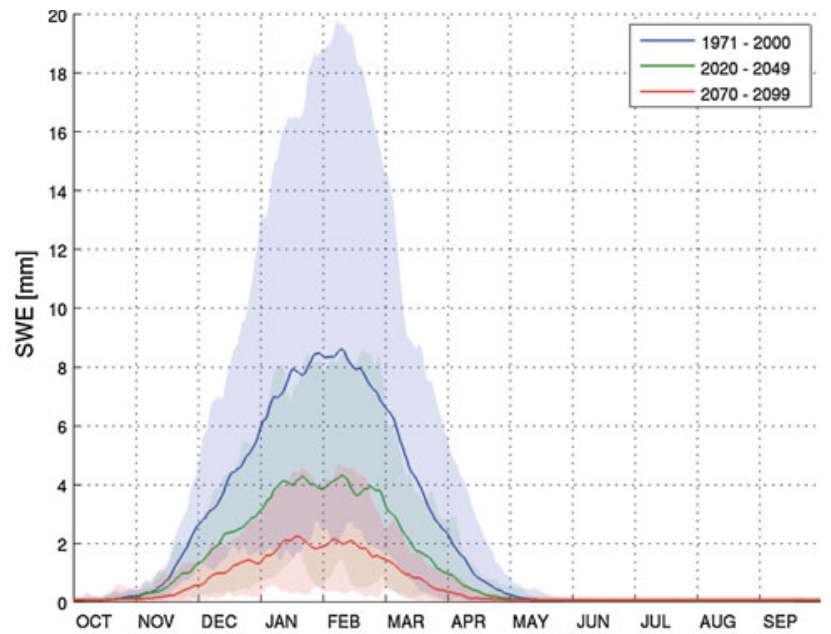

(c) $1500-2000 \mathrm{~m}$ asl

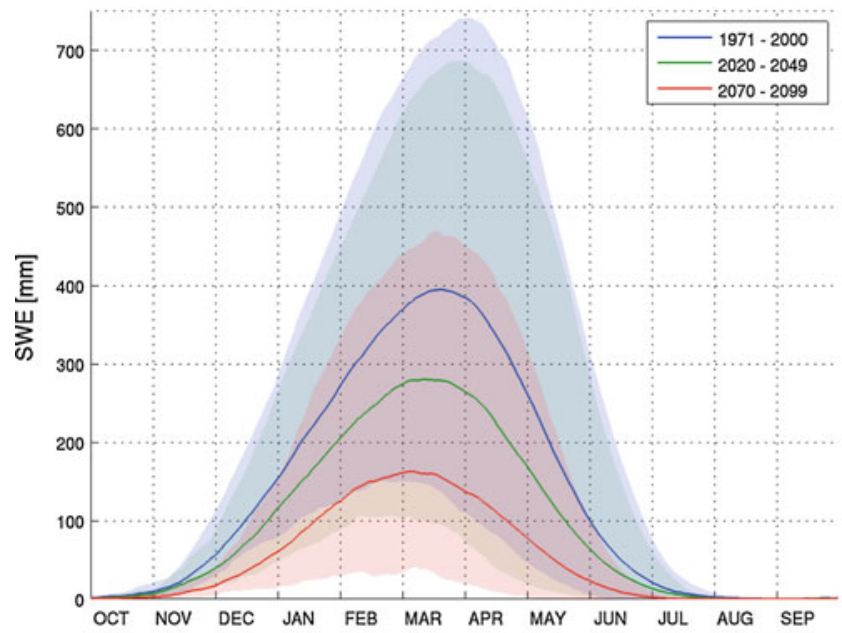

(e) $>2500 \mathrm{~m}$ asl

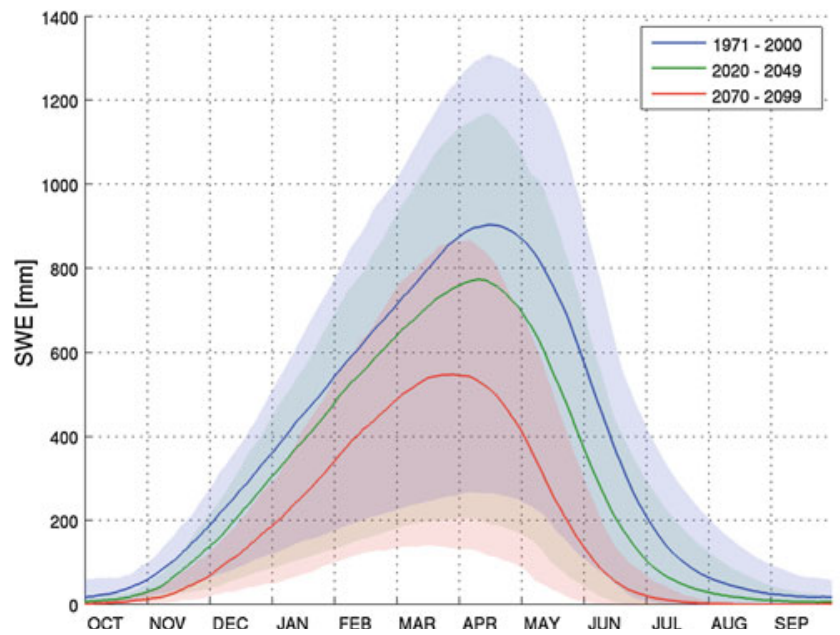

(b) $1000-1500 \mathrm{~m}$ asl

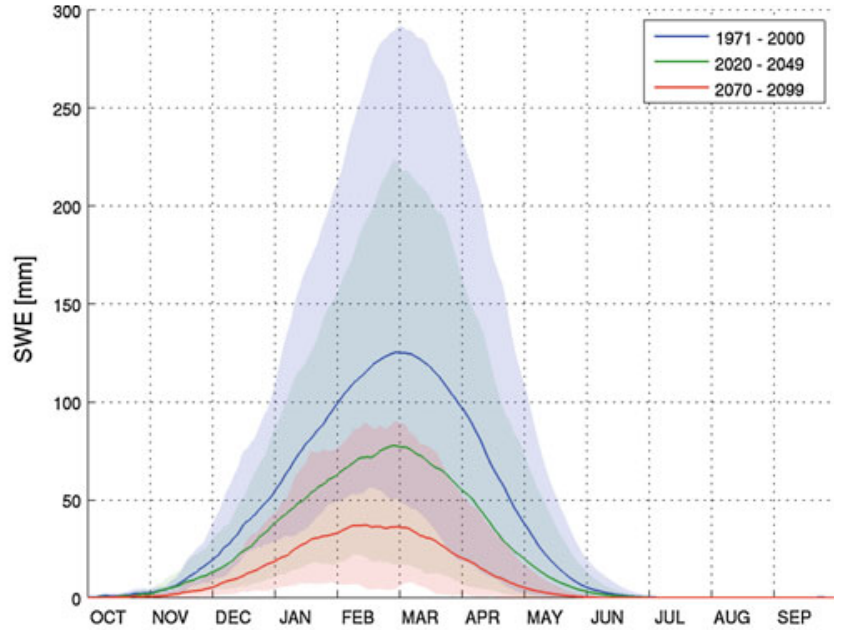

(d) $2000-2500 \mathrm{~m}$ asl

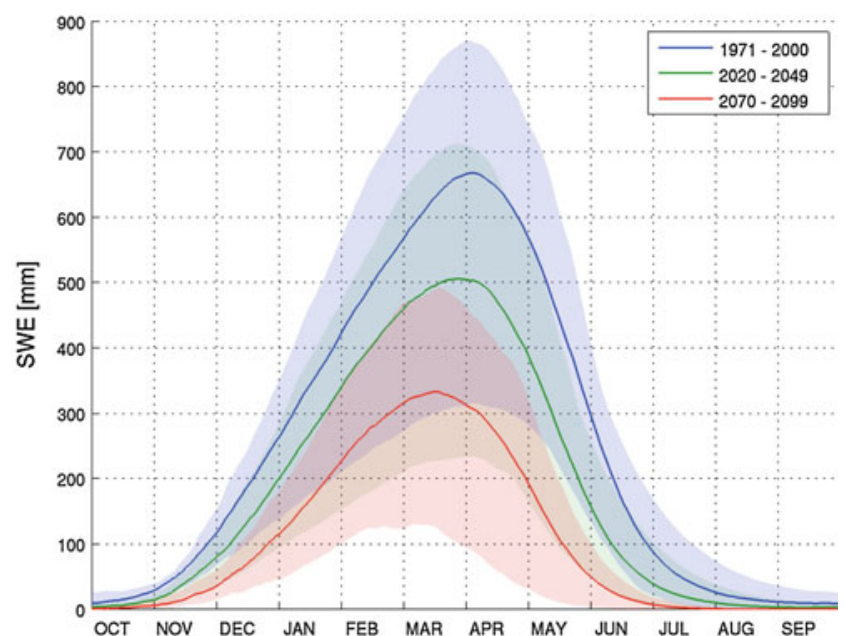

Fig. 7 Seasonal evolution of SWE [mm] for three distinct periods. The solid lines indicate the ensemble mean value of all RCMs for a given period whereas the shaded areas show the 10th to 90th percentile of the model range 


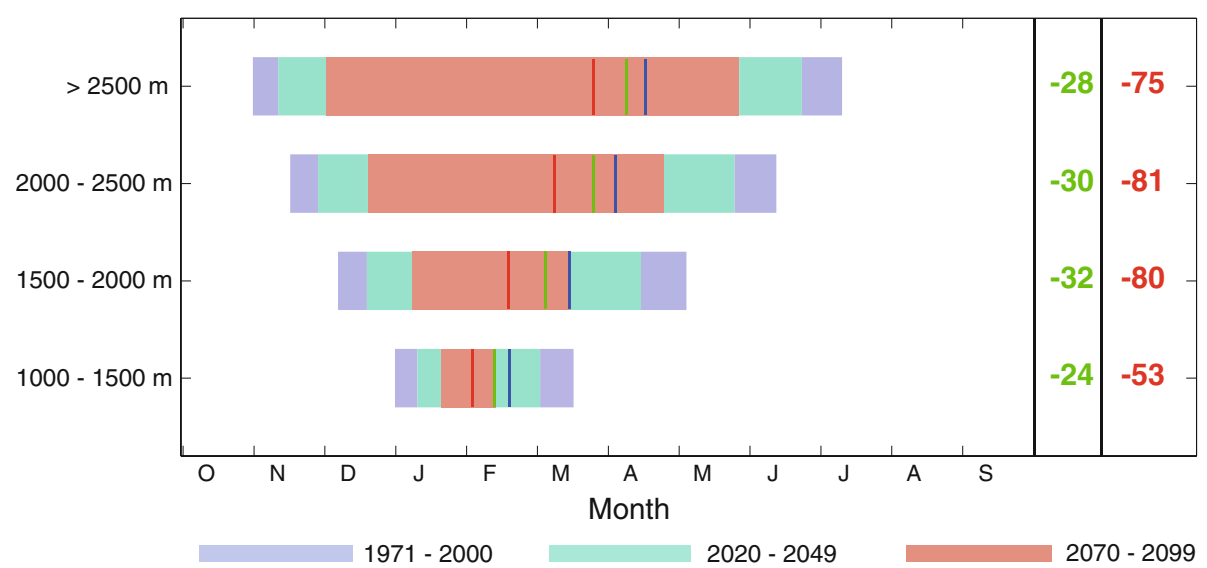

Fig. 8 Mean duration of the continuous snow cover period in four ARCs and for the ensemble mean of the GCM-driven experiments (the complete figure including all individual experiments can be found in the Electronic Supplementary Material, Fig. ESM 14). The blue bar indicates the period 1971-2000 whereas the green bar represents the period 2020-2049 and the red bar the period

mainly influenced by temperature. Atmospheric warming will generally lead to a faster melt of the snow cover and to an earlier meltout. This meltout will occur even earlier if less snow has been accumulated during the first half of the winter and, hence, the shortening of the snow season in spring is influenced by the combined effects of less accumulation and faster snow melt. This effect is analogous to the more pronounced change in the timing of snow cover meltout compared to the timing of snow cover onset when moving from (colder) high to (warmer) low elevations (see Fig. 8 and Fig. ESM 14).

The simulated changes of snow cover are ultimately connected to changes in the atmospheric forcing parameters, with temperature and precipitation changes presumably exerting the strongest influence (if temperature is assumed to serve as a proxy for the surface energy balance). An analysis of seasonal precipitation changes until the end of the twenty first century indicates a positive change for most RCMs and for most parts of the winter in all ARCs (Fig. ESM 11). However, the general increase in temperature, which is strongest at medium to high altitudes, mostly leads to a decrease of snowfall amounts. Only a few RCMs show an increase of snowfall in the two highest ARCs in mid-winter, and the ensemble mean change is predominantly negative except for slight positive changes in the highest ARC in February. Hence, temperature changes appear to be the dominant factor for the pronounced decrease in all analyzed snow parameters throughout the twenty first century. This is also reflected by (a) the strong decrease of the number of accumulation days, i.e. by a clear shortening of the accumulation period, while the mean accumulation rate only slightly changes in most experiments (except for SMHI-BCM; Fig. ESM 15)
2070-2099. The vertical lines within the bars show the average occurrence of peak SWE. The numbers in the two right columns indicate the change (in days) in the continuous snow cover duration for the periods 2020-2049 (green) and 2070-2099 (red) relative to the control period 1971-2000. The lowest ARC is not shown due to the lack of a continuous snow season at altitudes below $1,000 \mathrm{~m}$

and by (b) the pronounced influence of the driving GCM on the simulated temperature change (color scheme in Figure ESM 11) and the corresponding agreement of SWE changes in experiments driven by the same GCM (Fig. 6). Similar to the findings of Räisänen and Eklund (2012) and Räisänen (2008), snow cover in regions with today's temperatures close to the melting point are found to be most sensitive to projected future climate change. The dominant role of temperature changes for changes in snow cover is confirmed by Fig. 11, which relates the relative changes in mean winter SWE for the second scenario period to the simulated temperature changes in the individual ARCs. Except for the lowest ARC, strongly negative correlations are found, i.e. models with large temperature changes also experience strong reductions in mean winter SWE. The temperature change, in turn, strongly depends on the driving GCM (color scheme in Fig. 11). The obvious scatter around a simple linear relation can in parts be explained by the different baseline climate of the individual experiments, i.e. by the fact that the temperature level in the control climate is model dependent (see Fig. ESM 9) which, in turn, leads to different sensitivities of the SWE change to a given temperature change (see discussion above, as well as Räisänen and Eklund 2012).

\section{Conclusions}

In the present study, the simulated daily SWE in an ensemble of regional climate simulations was analyzed for mean winter SWE including its interannual variability, seasonal evolution of SWE and continuous snow cover duration in the European Alps. Most RCMs are capable of 


\section{(a) Mean SWE}

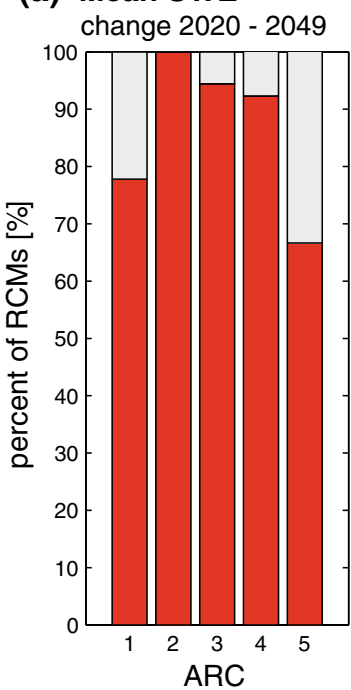

\section{(b) Start of continiuous snow cover}

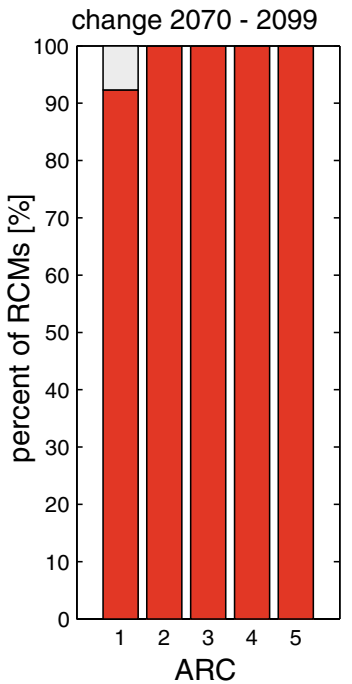

(c) Time of maximum SWE change 2020 - 2049
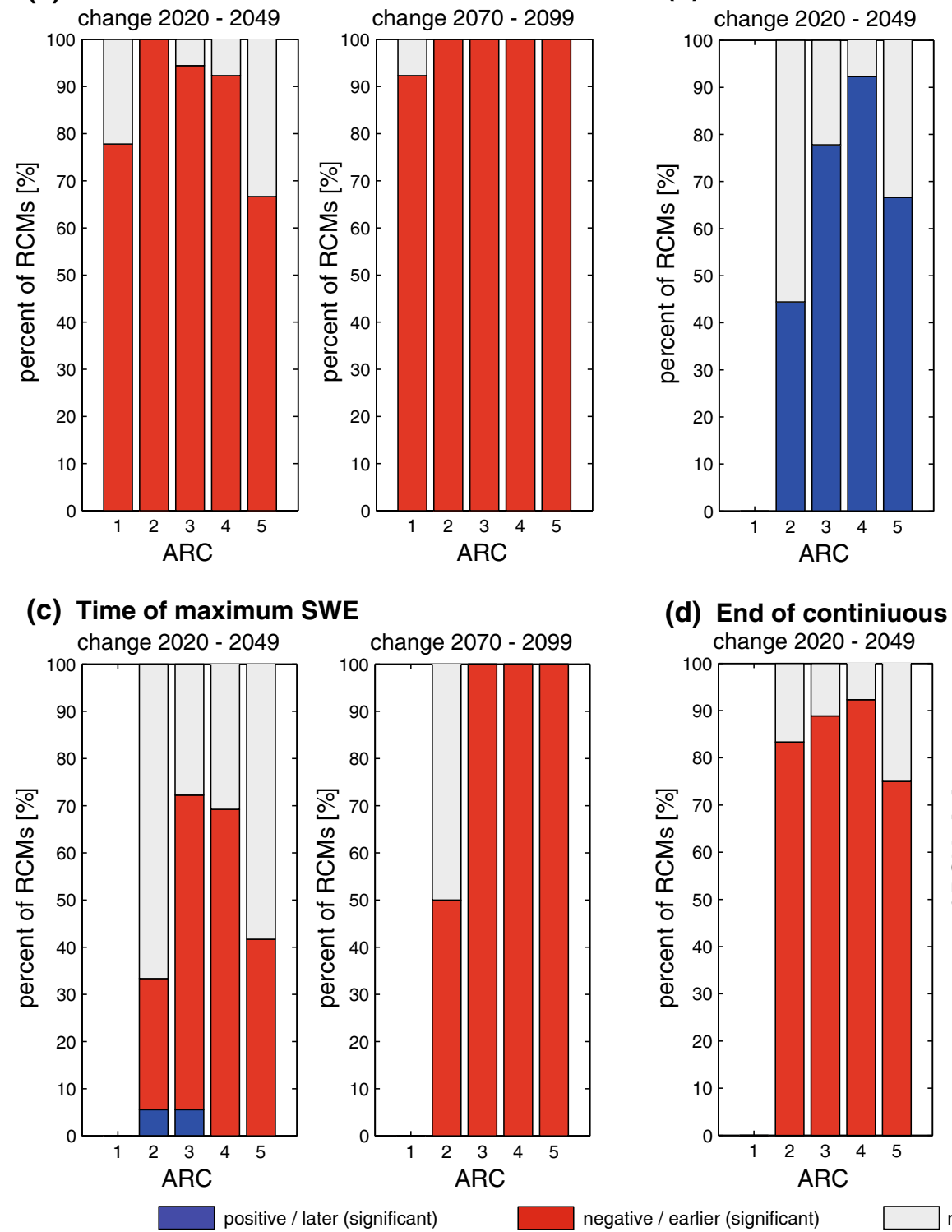

(d) End of continiuous snow cover

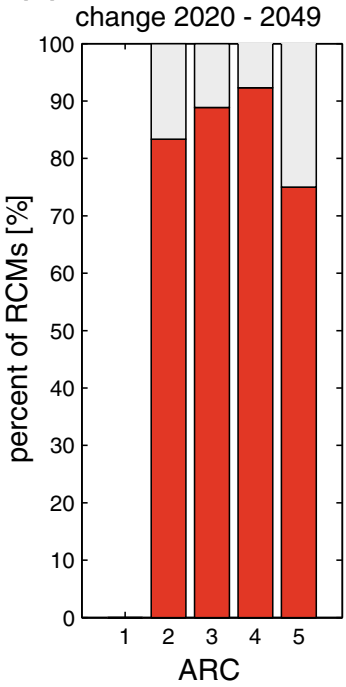

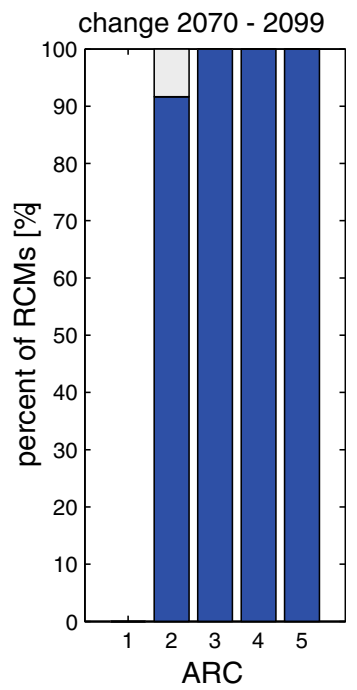

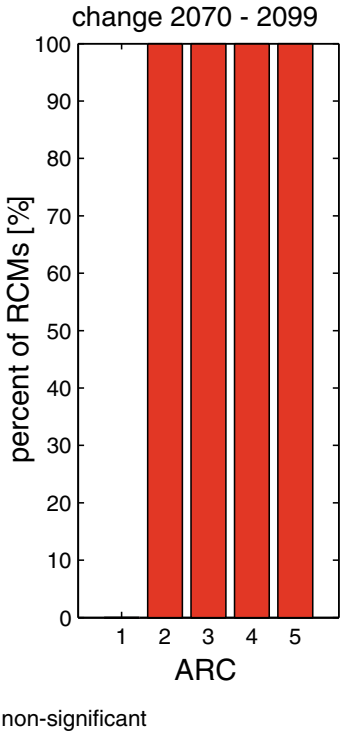

Fig. 9 Overview on the sign and the significance of changes in mean SWE (a) and the parameters characterizing the seasonal evolution of snow cover (b, c, d) in the RCM ensemble for the two scenario periods (left 2020-2049, right 2070-2099; significance level: 0.05). The numbers $1-5$ on the $x$ axes represent the different ARCs in ascending order $(<1,000 \mathrm{~m}, 1,000-1,500 \mathrm{~m}, 1,500-2,000 \mathrm{~m}$,

simulating the general characteristics of these parameters in the past decades (1971-2000). Among others, the spatial variability of mean winter SWE is well represented in most models and also the shape of the mean seasonal SWE evolution at different elevations. The multi-RCM ensemble mean accurately represents mean winter SWE at elevations below $1,500 \mathrm{~m}$ which is partly due to compensating biases. The temporal variability of observed mean winter SWE is well captured by the ERA40-driven experiments. However, both the ERA40- and the GCM-driven simulations
2,000-2,500 m, >2,500 m). Blue (red) indicates significant positive (negative) changes of mean SWE and significant shifts to later (earlier) times in the year. Panels $\mathbf{b}, \mathbf{c}$ and $\mathbf{d}$ exclude the lowest ARC due to the lack of a continuous snow season at altitudes below $1,000 \mathrm{~m}$

underestimate snow mass at low elevations (below 1,500 and $1,000 \mathrm{~m}$, respectively) and overestimate it at high elevations (above 1,500 and 1,000 $\mathrm{m}$, respectively). The positive SWE biases at higher elevations could originate from a positive precipitation bias in these areas whereas the reason for the negative SWE biases in lower regions is not readily explainable by only considering precipitation and temperature as proxies for snow. The underestimation of snow at low elevations might, in contrast, be related to the poor resolution of topographical structures by the RCM orographies and the 
Fig. 10 Agreement of 11 RCMs on the hundred-days rule (including the "7-out-of-10winters" extension) for two different snow depth thresholds and based on $200 \mathrm{~m}$ elevation bins. The color shading represents the percentage of RCMs that indicate a fulfillment of the hundred-days rule in a given decade (red colors less than $50 \%$, blue colors more than $50 \%$ ). Prior to the counting of models, the simulated SWE was biascorrected and averaged over each elevation bin for each individual model (a) RCM agreement on hundred-days-rule for snow depth threshold of $0.3 \mathrm{~m}$

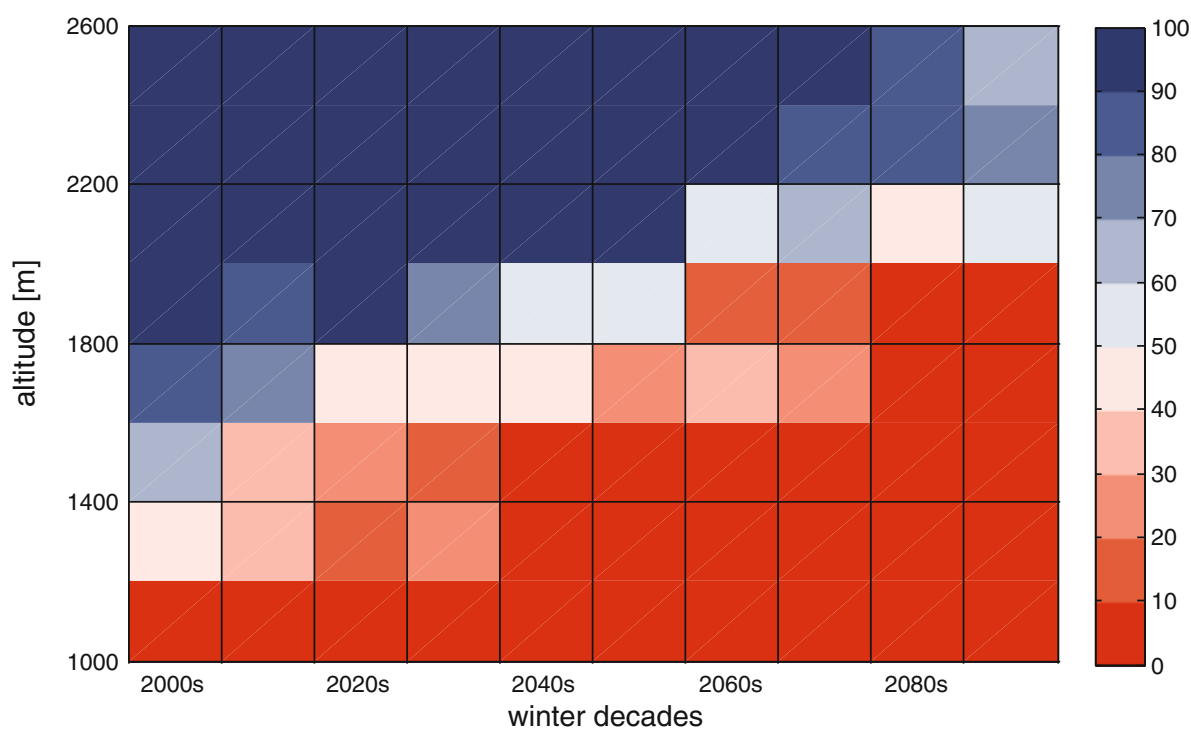

(b) RCM agreement on hundred-days-rule for snow depth threshold of $0.5 \mathrm{~m}$

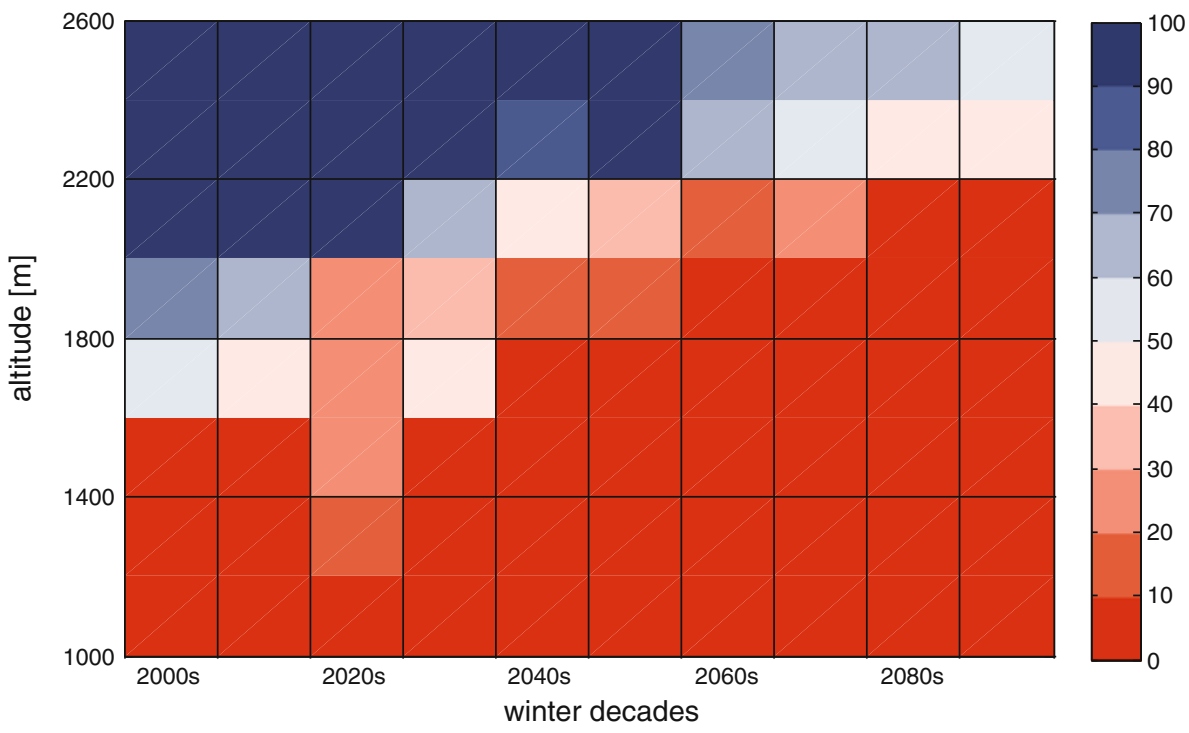

neglect of subgrid topographic variability by their land surface schemes. These simplifications prevent the accumulation of snow in the (subgrid-scale) upper parts of low-elevation grid cells and potentially lead to an underestimation of snow cover. This is consistent with the apparent underestimation of the mean daily accumulation rate at low elevations in the ERA40driven RCMs. Indeed, Giorgi et al. (2003) showed that the inclusion of a subgrid topography scheme in an RCM can lead to an increase of simulated snow cover and a more realistic simulation of snow cover characteristics in complex Alpine terrain.

The projections for the climate of the twenty first century indicate the strongest reduction of mean winter SWE at low elevations (about $-70 \%$ for elevations below $1,000 \mathrm{~m}$ by the end of the century). The changes of the analyzed snow parameters appear to be strongest in regions where temperatures are close to the melting point for large parts of the winter. A strong influence of the winter temperature change, which considerably depends on the driving GCM, on the relative change of mean winter SWE can be identified. Evaluation of the continuous snow cover duration indicates an asymmetrical shortening of the snow cover season with a stronger reduction at the end of the winter. The peak values of SWE are shifted towards earlier times in winter. Please note that, although a large model ensemble consisting of several GCMs and RCMs is used in our study, the identified uncertainty ranges of future snow cover changes are likely to underestimate the full uncertainty as only SRES A1B is considered and emission scenario uncertainty is not accounted for. 
(a) $<1000 \mathrm{~m}$ as

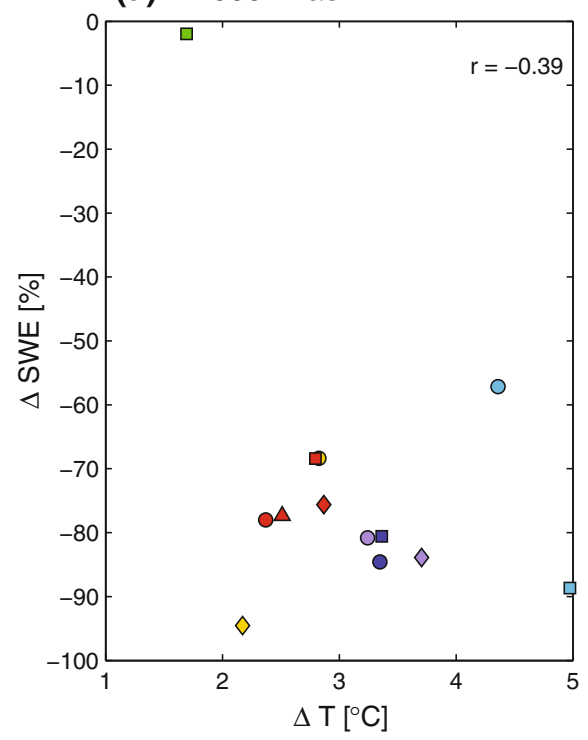

(d) $2000-2500 \mathrm{~m}$ asl

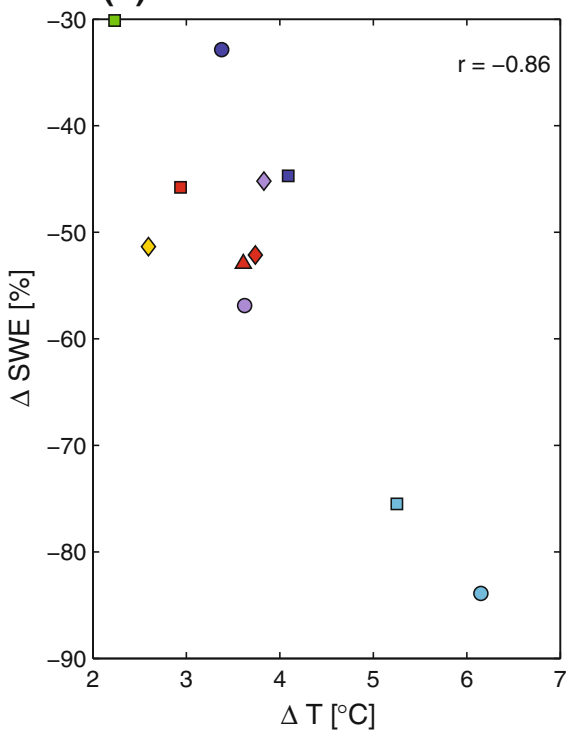

(b) $1000-1500 \mathrm{~m}$ asl

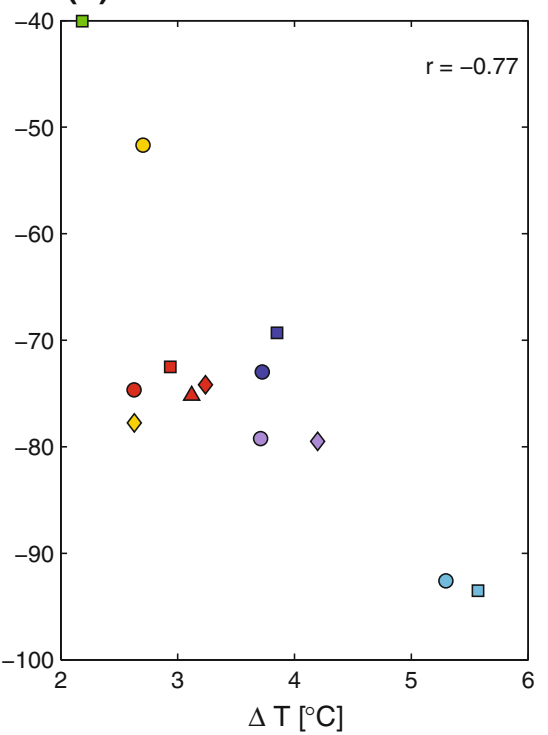

(e) $>2500 \mathrm{~m}$ asl

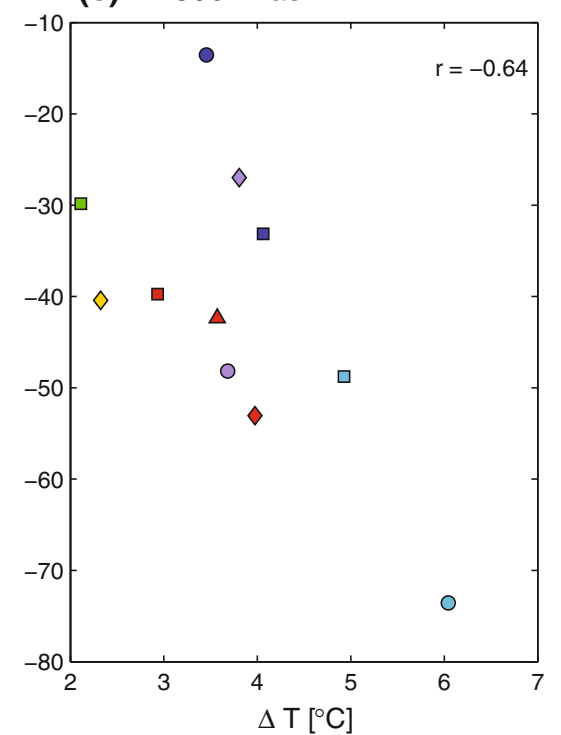

(c) $1500-2000 \mathrm{~m}$ asl

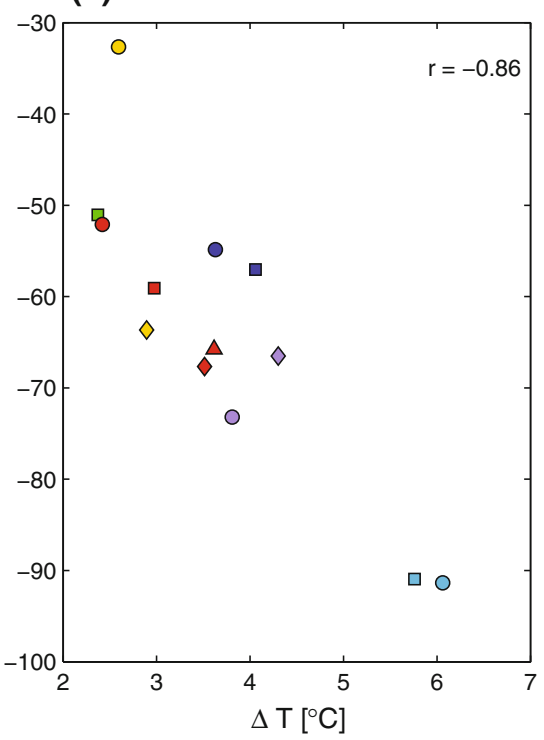

Fig. 11 Relation between changes in mean winter SWE [\%] and mean winter temperature $\left[{ }^{\circ} \mathrm{C}\right]$ in the individual ARCs and for the individual RCMs (2070-2099 with respect to 1971-2000). The experiments are colored according to the driving GCM

The strong reduction of mean winter SWE in the Alps is expected to have major impacts for winter tourism. Many ski-regions have mean elevations below 2,000 $\mathrm{m}$ and are therefore especially vulnerable to climate change. The shortening of the snow season and the temporal shift of peak SWE to earlier times may lead to larger alpine river discharge in spring and reduced summer discharge (e.g. Bosshard et al. 2011), which is also likely to affect hydropower generation (e.g. Hänggi et al. 2011; Stähli et al. 2011). A shortening of the snow cover season can also be expected to have strong impacts on Alpine ecology, e.g. on hibernating mammals and on the timing of the vegetation cycle.
Obviously, a limitation of the analyzed RCM output is the comparably low horizontal resolution and the simple parameterization of some snow-related processes (concerning, for example, the influence of forests or refreezing of meltwater). The coarse RCM resolution does not allow to accurately capture topographically controlled processes that exert an important influence on snow cover, such as shading, exposition and the elevation-distribution of snow on a subgrid scale. Also the biased atmospheric forcing provided by the atmospheric model components in fully coupled RCM experiments will ultimately introduce biases in the simulated SWE. These biases, in turn, can again partly be attributed to the comparatively coarse horizontal 
resolution at which RCMs operate and which does not allow to resolve, for instance, winter inversions and cold air pools relevant for snow preservation. Despite these limitations our results closely agree with previous studies applying more complex land surface models at higher resolution, indicating that the direct analysis of surface snow cover in high-resolution RCMs is feasible even in regions of high topographic variability such as the Alps. A further limitation of our approach is the fact that the orography of a $25 \mathrm{~km} \mathrm{RCM}$ grid does not represent elevations above approximately 2,700 $\mathrm{m}$ in the Alps. Ergo the RCMs cannot provide climate change information for elevations beyond this limit. This is a major disadvantage for cryospheric impact research as a considerable amount of snow, permafrost and glacier ice is stored in high elevations and climate change can be expected to considerably depend on surface elevation (e.g. Kotlarski et al. 2012). However, the resolution of RCMs is constantly increasing (it will soon reach to $10 \mathrm{~km}$ limit for decadal-scale experiments) and snow-related processes are represented in more and more detail. These improvements can be expected to lead to a more accurate representation of snow cover and its spatial and temporal variability in RCMs and will allow evaluations of future changes in snow cover at altitudes above $2,700 \mathrm{~m}$.

Acknowledgments The ENSEMBLES data used in this work was funded by the EU FP6 Integrated Project ENSEMBLES (Contract number 505539) whose support is gratefully acknowledged. We also acknowledge the E-OBS dataset from the ENSEMBLES project and the data providers in the ECA\&D project (http://eca.knmi.nl). Partial funding for this study has been provided by the Swiss National Science Foundation via NCCR Climate. We would also like to thank Daniel Lüthi and C2SM for model and data support, and three anonymous reviewers for their very helpful and constructive input.

\section{References}

Abegg B (1996) Klimaänderung und Tourismus. Klimafolgenforschung am Beispiel des Wintertourismus in den Schweizer Alpen. Vdf Zurich, Zurich

Abegg B, Agrawala S, Crick F, de Montfalcon A (2007) Climate change impacts and adaptation in winter tourism. In: Agrawala $S$ (ed) Climate change in the European Alps. Adapting winter tourism and natural hazards management. OECD, Paris, pp 25-60

Adam JC, Lettenmaier DP (2003) Adjustment of global gridded precipitation for systematic bias. J Geophys Res 108:4257. doi: 10.1029/2002JD002499

Armstrong RL, Brun E (2008) Snow and climate: physical processes, surface energy exchange and modeling. Cambridge University Press, Cambridge

Bavay M, Lehning M, Jonas T, Löwe H (2009) Simulations of future snow cover and discharge in Alpine headwater catchments. Hydrol Process 23:95-108. doi:10.1002/hyp.7195

Beniston M, Keller F, Koffi B, Goyette S (2003) Estimates of snow accumulation and volume in the Swiss Alps under changing climatic conditions. Theor Appl Climatol 76:125-140. doi: 10.1007/s00704-003-0016-5

Bosshard T, Carambia M, Goergen K, Kotlarski S, Krahe P, Zappa M, Schär C (2011) Quantifying uncertainty sources in hydrological climate impact scenarios. Water Resour Res (submitted)

Brown RD, Mote PW (2009) The response of northern Hemisphere snow cover to a changing climate. J Clim 22:2124-2145. doi: 10.1175/2008JCLI2665.1

Buerki R (2000) Klimaänderung und Wintertourismus im Obertoggenburg. In: Natur Forschung in der Region St. Gallen, Berichte der St. Gallischen (eds) Naturwissenschaftlichen Gesellschaft. 89:97-109

CH2011 (2011) Swiss climate change scenarios CH2011. Published by C2SM, MeteoSwiss, ETH, NCCR Climate, and OcCC. Zurich, Switzerland, ISBN 978-3 033-03065-7, 88 pp [available at http://www.ch2011.ch]

Christensen JH, Christensen OB (2007) A summary of the PRUDENCE model projections of changes in European climate by the end of this century. Clim Change 81:7-30. doi:10.1007/s 10584-006-9210-7

Dutra E, Kotlarski S, Viterbo P, Balsamo G, Miranda PMA, Schaer C, Bissolli P, Jonas T (2011) Snow cover sensitivity to horizontal resolution, parameterizations and atmospheric forcing in a land surface model. J Geophys Res 116:D21109

Egli L, Jonas T, Meister R (2009) Comparison of different automatic methods for estimating snow water equivalent. Cold Reg Sci Technol 57:107-115. doi:10.1016/j.coldregions.2009.02.008

Elsasser H, Buerki R (2002) Climate change as a threat to tourism in the Alps. Clim Res 20:253-257

Foppa N, Stoffel A, Meister R (2007) Synergy of in situ and space borne observation for snow depth mapping in the Swiss Alps. Int J Appl Earth Observ Geoinf 9(3):294-310. doi:10.1016/j.jag. 2006.10.001

Fowler HJ, Blekinsop S, Tebaldi C (2007) Linking climate change modelling to impacts studies: recent advances in downscaling techniques for hydrological modeling. Int $\mathrm{J}$ Climatol 27:1547-1578. doi:10.1002/joc. 1556

Fyfe JC, Flato GM (1999) Enhanced climate change and its detection over the rocky mountains. J Clim 12:230-243

Giorgi F, Hurrell JW, Marinucci MR (1997) Elevation dependency of the surface climate change signal: a model study. Clim Change 10:288-296

Giorgi F, Francisco R, Pal J (2003) Effects of a subgrid-scale topography and land use scheme on the simulation of surface climate and hydrology. Part I: effects of temperature and water vapor disaggregation. J Hydromet 4:317-333

Hall A (2004) The role of surface albedo feedback in climate. Am Meteorol Soc 17:1550-1568

Hänggi P, Angehrn S, Bosshard T, Helland E, Job D, Rietmann D, Schädler B, Schneider R, Weingartner R (2011) Einfluss der Klimaänderung auf die Stromproduktion der Wasserkraftwerke Löntsch und Prättigau. Wasser Energie Luft 103(4):292-299

Hantel M, Hirtl-Wielke L-M (2007) Sensitivity of Alpine snow cover to European temperature. Int J Clim 27:1265-1275

Hantel M, Maurer C (2011) The median winter snowline in the Alps. Meteorol Z 20(3):267-276

Haylock MR, Hofstra N, Klein-Tank AMG, Klok EJ (2008) A European daily high-resolution gridded data set of surface temperature and precipitation for 1950-2006. J Geophys Res 113:D20119. doi:10.1029/2008JD01201

Henderson GR, Leathers DJ (2010) European snow cover extent variability and associations with atmospheric forcings. Int $\mathbf{J}$ Climatol 30:1440-1451. doi:10.1002/joc.1990

Jonas T, Rixen C, Sturm M, Stoeckli V (2008) How alpine plant growth is linked to snow cover and climate variability. J Geophys Res 113:G03013. doi:10.1029/2007JG000680 
Jonas T, Marty C, Magnusson J (2009) Estimating the snow water equivalent from snow depth measurements in the Swiss Alps. J Hydrol 378:161-167. doi:10.1016/j.jhydrol.2009.09.021

Kobierska F, Jonas T, Zappa M, Bavay M, Magnusson J, Bernasconi SM (2012) Future runoff from a partly glacierized watershed in Central Switzerland: a two-model approach. Adv Water Resour (submitted)

Kotlarski S, Bosshard T, Lüthi D, Pall P, Schär C (2012) Elevation gradients of European climate change in the regional climate model COSMO-CLM. Clim Change (in press). doi:10.1007/ s10584-011-0195-5

Laternser M, Schneebeli M (2003) Long-term snow climate trends of the Swiss alps (1931-99). Int J Climatol 23:733-750. doi: 10.1002/joc. 921

Lenderink G, Buishand A, van Deursen W (2007) Estimates of future discharges of the river Rhine using two scenario methodologies: direct versus delta approach. Hydrol Earth Syst Sci 11(3): $1145-1159$

Magnusson J, Jonas T, López-Moreno I, Lehning M (2010) Snow cover response to climate change in a high alpine and halfglacierized basin in Switzerland. Hydrol Res 41(3-4):230-240

Marchand PJ (1996) Life in the cold: an introduction to winter ecology. University Press of New England, Hanover

Martin E, Etchevers P (2005) Impact of climatic changes on snow cover and snow hydrology in the French Alps. Adv Glob Change Res 23:235-242. doi:10.1007/1-4020-3508-X_24

Marty C (2008) Regime shift of snow days in Switzerland. Geophys Res Lett 35:L12501. doi:10.1029/2008GL022998

Nakicenovic N, Swart R (eds) (2000) Emission scenarios. A special report of working group III of the Intergovernmental Panel on Climate Change. Cambridge University Press, England

Norris JR, Wild M (2007) Trends in aerosol radiative effects over Europe inferred from observed cloud cover, solar "dimming", and solar "brightening". J Geophys Res 112:D08214. doi:10.1029/ 2006JD007794

Räisänen J (2008) Warmer climate: less or more snow? Clim Dyn 30:307-319. doi:10.1007/s00382-007-0289-y

Räisänen J, Eklund J (2012) 21st century changes in snow climate in Northern Europe: a high-resolution view from ENSEMBLES regional climate models. Clim Dyn 38:2575-2591. doi:10.1007/ s00382-011-1076-3

Rangwala I, Miller JR (2012) Climate change in mountains: a review of elevation-dependent warming and its possible causes. Clim Change (in press). doi:10.1007/s10584-012-0419-3

Rockel B, Will A, Hense A (2008) The regional climate model COSMO-CLM (CCLM). Meteorol Z 17(4):347-348

Salzmann N, Mearns L (2011) Assessing the performance of multiple regional climate model simulations for seasonal mountain snow in the Upper Colorado River Basin. J Hydrometeor (in press). doi:10.1175/2011JHM1371.1

Schär C, Davis TD, Frei C, Wanner H, Widmann M, Wild M, Davis HC (1998) Views from the Alps: regional perspectives on climate. MIT press, Boston

Scherrer SC, Appenzeller C (2006) Swiss Alpine snow pack variability: major patterns and links to local climate and largescale flow. Clim Res 32:187-199

Scott D, McBoyle G (2007) Climate change adaptation in the ski industry. Mitig Adapt Strat Glob Change 12:1411-1431

Scott D, McBoyle G, Mills B (2003) Climate change and the skiing industry in southern Ontario (Canada): exploring the importance of snowmaking as a technical adaptation. Clim Res 23:171-181

Sevruk B (1997) Regional dependency of precipitation-altitude relationship in the Swiss Alps. Clim Change 36:355-369

Stähli M, Raymond-Pralong M, Zappa M, Ludwig A, Paul F, Bosshard T, Dupraz C (2011) Auswirkungen auf die Wasserverfügbarkeit und Stromproduktion an den Beispielen Oberhasli und Mattmark. Wasser Energie Luft 103(4):285-291

Steiger R (2010) The impact of climate change on ski season length and snowmaking requirements in Tyrol, Austria. Clim Res 43:251-262. doi:10.3354/cr00941

Uppala SM, Kallberg PW, Simmons AJ, Andrae U, Da Costa Bechtold V, Fiorino M, Gibson JK, Haseler J, Hernandez A, Kelly GA, Li X, Onogi K, Saarinen S, Sokka N, Allan RP, Andersson E, Arpe K, Balmaseda MA, Beljaars ACM, Van de Berg L, Bidlot J, Bormann N, Caires S, Chevallier F, Dethof A, Dragosavac M, Fisher M, Fuentes M, Hagemann S, Holm E, Hoskins BJ, Isaksen L, Janssen PAEM, Jenne R, McNally AP, Mahfouf J-F, Morcrette J-J, Rayner NA, Saunders RW, Simon P, Sterl A, Trenberth KE, Untch A, Vasiljevic D, Viterbo P, Woollen J (2005) The ERA-40 re-analysis. Quart J Roy Meteor Soc 131:2961-3012

van der Linden P, Mitchell JFB (2009) ENSEMBLES: climate change and its Impacts: summary of research and results from the ENSEMBLES project. Met Office Hadley Centre, Exeter 160 pp

Voigt T, Fuessel HM, Gaertner-Roer I, Huggel C, Marty C, Zemp M (2010) Impacts of climate change on snow, ice, and permafrost in Europe: observed trends, future projections, and socioeconomic relevance-ETC./ACC Technical Paper 2010/13

Wielke L-M, Haimberger L, Hantel M (2004) Snow cover duration in Switzerland compared to Austria. Meteorol Z 13(1):13-17

Wood AW, Leung LR, Sridhar V, Lettenmaier DP (2004) Hydrologic implications of dynamical and statistical approaches to downscaling climate model outputs. Clim Change 62:189-216

Zemp M, Hoelzle M, Haeberli W (2007) Distributed modelling of the regional climatic equilibrium line altitude of glaciers in the European Alps. Glob Planet Change 56:83-100 